\title{
Applying ex post index decomposition analysis to final energy consumption for evaluating European energy efficiency policies and targets
}

\author{
Matthias Reuter (D) Martin K. Patel • \\ Wolfgang Eichhammer
}

Received: 18 December 2017 / Accepted: 20 December 2018 /Published online: 11 January 2019

(C) The Author(s) 2019

\begin{abstract}
This paper aims to unravel the effects of both policies and autonomous developments driving the changes of final energy consumption for the European Union (EU28) and its member states complemented with an in-depth analysis of two EU member states, Germany and Poland, for the period of 2000 to 2015 by the logarithmic mean Divisia index methodology (LMDI). We examine the influences on the changes in final energy consumption for each of the five main demand sectors at aggregated level and at a more detailed level of residential end-uses, transport modes and industrial sub-sectors. With the second level, we provide insights into the effects of policies from a European and national perspective. Our analysis shows that final energy consumption in the EU28 is primarily influenced by an increase in energy efficiency in industry followed by households. For the latter, the energy savings were mainly realised in space heating. The main counteracting drivers were increasing
\end{abstract}

M. Reuter $(\bowtie) \cdot$ W. Eichhammer

Fraunhofer Institute for Systems and Innovation Research (ISI), Breslauer Straße 48, 76139 Karlsruhe, Germany

e-mail: matthias.reuter@ isi.fraunhofer.de

\section{K. Patel}

Department F.-A. Forel for Environmental and Aquatic Sciences, University of Geneva, Geneva, Switzerland

W. Eichhammer

Copernicus Institute of Sustainable Development, Utrecht University, Utrecht, The Netherlands economic activity and the rising demand for higher comfort and social factors, such as a declining household size. Germany shows relatively low energy efficiency improvements in industry, but strong energy efficiency gains in households followed by transport. Poland's transport, however, is responsible for a strong increase in final energy consumption mainly through increased activity, while here the sector industry-despite strong effects of increased activity - in total shows a significant reduction in energy consumption through energy efficiency improvements.

Keywords Policy evaluation · Energy efficiency targets · Final energy · Decomposition analysis . European Union

\section{Introduction}

The final energy consumption in the European Union of 1062 Mtoe in 2014 was a record low in the period since 1994 and already surpassed the $20 \%$ energy efficiency objective of 1086 Mtoe targeted for the year 2020 (Bertoldi et al. 2016). This target is measured against the business-as-usual scenario (BAU) of PRIMES 2007 (Capros et al. 2008) (Fig. 1). In 2015, the total final consumption slightly increased to 1082 Mtoe, practically coinciding with the $20 \%$ objective and reaching the same level as 1995. The updated targets of the EU's 2030 Energy Strategy require at least $27 \%$ energy savings 


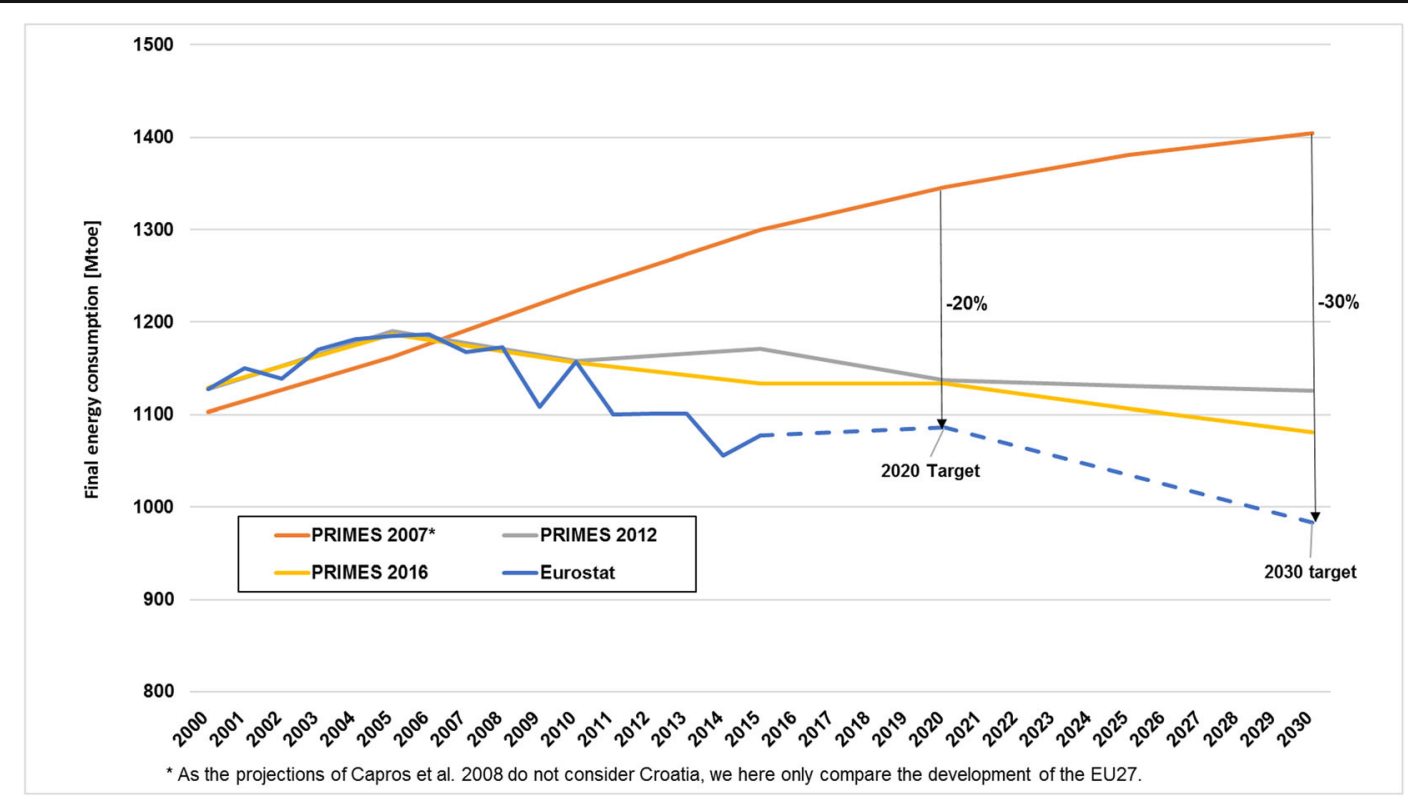

Fig. 1 Development of final energy consumption in the EU28 for the period of 2000 to 2015 compared to the reference scenarios developed in 2007, 2012 and 2016 and the energy efficiency targets (Capros et al. 2008, 2013, 2016)

compared with the same BAU scenario (European Commission 2014) and the present proposal of the EU Commission is even aiming at $30 \%$ energy savings (European Commission 2016a). Based on the energy statistics of 2015, the gap to be closed in the European Union for reaching the 2030 objectives of $20 \%$ and $30 \%$ are below $6 \%$ and $10 \%$, respectively.

It should be noted that the PRIMES 2007 reference scenario is a baseline developed before the economic crisis of 2008 and has been maintained by policy makers to ensure consistency of progress tracking over time. This baseline has been corrected successively during each new projection, which occurred every 2 to 3 years (see for example PRIMES 2012 (Capros et al. 2013) and PRIMES 2016 (Capros et al. 2016) baselines in Fig. 1), which are considerably lower than the original PRIMES 2007 baseline.

Most of the total reduction of $4.5 \%$ between 2000 and 2015 was due to the industry sector with a reduction of almost $18 \%(-1.3 \% / a)$ followed by the sector agriculture/forestry/fishing with $-16 \%$ $(-1.2 \% / a)$. This development was counteracted by a rising energy consumption in the sector services $(+21 \%)$. The final energy demand between 2000 and 2015 shows two distinct phases: up to 2006 final energy was still increasing, while it has been experiencing a decreasing trend since then. The even higher reduction of almost $8 \%$ in the period of 2007 to 2015 is partly due to the decrease of final energy consumption of the transport sector by $6.5 \%$.

To identify the key determining factors for these changes in final energy consumption and their impact, we conducted an index decomposition analysis (IDA) for final energy consumption (FEC) of all member states of the EU28. We focused on 2000 to 2015 , as this period shows a good statistical coverage for all EU member states and is relevant for a number of energy efficiency related policies in the EU. In some interesting cases, we also consider the period of 2007 to 2015 to analyse the development directly following an economic recession. The most relevant policies related to energy efficiency in these periods are as follows:

- The European Energy Efficiency Directive 2012/27/ EU (EED) (European Commission 2012)

- The Energy Performance of Buildings Directive 2010/31/EU (EPBD) (European Council 2014)

- The Ecodesign Directive 2009/125/EC (European Parliament; Council of the European Union 2009b)

- The Energy Labelling Directive 2010/30/EU (European Parliament, Council of the European Union 2010), which was replaced recently with Regulation (EU) 2017/1369 (European 
Parliament; Council of the European Union 2017)

- The European Emissions Trading Scheme (EUETS) (European Parliament; Council of the European Union 2009c)

- The Effort Sharing Decision 406/2009/EC (European Parliament; Council of the European Union 2009a)

- The Industrial Emissions Directive 2010/75/EU;

- The Regulation (EC) No 443/2009 regarding $\mathrm{CO}_{2}$ emissions of new passenger cars (European Parliament; Council of the European Union 2009d) and a similar regulation for light commercial vehicles

- The Car Labelling Directive 1999/94/EC (European Parliament; Council of the European Union 1999)

At the same time, there are a large number of national energy efficiency policies, which also contribute to improving energy efficiency. For an overview, see the ODYSSEE-MURE database (ODYSSEE-MURE 2017) on energy efficiency policies and trends.

Some of these policies directly affect final energy consumption, while others such as the EU-ETS (the effort sharing decision and the industrial emissions directive) only indirectly affect the demand side. These mostly aim to reduce emissions such as carbon dioxide and other GHG or harmful gases to protect the environment and human health due to energy conversion or industrial activity.

In this paper, we examine developments of final energy consumption in the European Union and its member states, by considering those factors which had a strong impact on final energy consumption by decomposing energy use on the demand side by sectors and subsectors, transport modes and enduses.

Index decomposition analysis is commonly used for primary or final energy consumption (e.g. Wang et al. (2014), Zhang et al. (2018) and Song and Zhang (2017) for final energy consumption in China; Timma and Blumberga (2014) for the energy sector in Latvia; Colinet Carmona and Román Collado (2016) for energy consumption in Andalusia; Stenqvist (2015) for the energy consumption of the Swedish pulp and paper industry; and Kerimray et al. (2018) for energy intensity in Kazakhstan) and GHG emissions in individual countries or regions (Goh et al. 2018; Wachsmuth and Duscha 2018;
Kopidou and Diakoulaki 2017; Wang et al. 2017; $\mathrm{Xu}$ et al. 2017; Karmellos et al. 2016; Xu et al. 2016a, b; Colinet Carmona and Román Collado 2016; Moutinho et al. 2016; Nie et al. 2016; Xu et al. 2014; Pardo Martínez and Silveira 2013). Recently, also different aspects of air pollution other than GHG emissions were studied using index decomposition (e.g. Xu et al. (2019) and Li et al. (2018)).

Past studies using index decomposition analysis on energy consumption often considered only the final energy consumption of one single sector, such as industry, households or transport focussing on one single country (e.g. Holzmann et al. (2013) residential in Austria, Chong et al. (2017) for residential in the Guangdong Province, Zhang et al. (2016) and Zhang and Bai (2018) for the residential energy consumption in the Jiangsu Region and Shandong of China; Achour and Belloumi (2016) transport in Tunisia or China (Zhang et al. 2011) and Kim (2017) on manufacturing in Korea). The sectors agriculture, services, transportation and industry in Turkey are analysed by Yilmaz and Atak (2010).

Marrero and Ramos-Real (2013) analysed the changes in energy intensity in the EU15 from 1991 to 2005. Fernández González et al. (2014) studied the aggregated final energy consumption in the EU27. For an ex ante analysis, Smit et al. (2014) examined the underlying effects of the developments in the projections of PRIMES 2007 and PRIMES 2013. Xu and Ang (2014) give an overview of several studies analysing final energy consumption in the residential sector listing 20 publications from 1997 to 2013.

A comprehensive analysis of the development of final energy consumption and its driving factors on a sectoral level can function as an overarching analysis providing additional insights.

In this paper, we aim to provide such analysis to show the effects of energy policies in the European context and on a national level. We try to answer the question of what influence different selected drivers have on final energy consumption in the demand sectors and how strong the effects are. We also try to link these developments to the main energy and climate policies of these sectors and to derive policy recommendations.

To the best of the authors' knowledge, so far in other recent studies, this has not been done for the European Union as a whole and its member states for all relevant demand sectors in a uniform methodological framework. 
In Reuter et al. (2017), we analysed the effects underlying the changes in primary energy consumption in the EU28 and its member states. We found that the reduction of final energy consumption played a major role in decreasing primary energy consumption compared to other factors, explaining approximately $65 \%$ of the total reduction. In contrast, other developments, e.g. increased renewable energy in the energy sector, contributed relatively little. This is a remarkable outcome also in view of the predominating understanding according to which energy efficiency policies have so far not been sufficiently effective. It is thus essential to better understand the developments on the energy demand side and to analyse the developments underlying the changes in final energy consumption, which is the topic of this paper.

The value added of our work lies in the comprehensive analysis of all sectors of the demand side affecting the final energy consumption within one comprehensive methodological framework and based on a consistent data corpus. In addition, this study comprises all member states of the European Union, shedding light on the underlying developments of the region as a whole. We are therefore convinced that the present work represents a novelty and offers clear added value to past studies as these only consider a single country or demand sector.

This analysis and the results may be useful for the design and implementation of future energy policy as policy makers are currently facing crucial decisions regarding the achievement of targets set for the near and distant future in the European Union and globally.

\section{Methods and data}

\section{Decomposition method}

For analysing the underlying effect of changes in the final energy consumption, in this study, we use the index decomposition analysis (IDA) based on the socalled logarithmic mean Divisia index method (LMDI), which is widely adopted. Different methods were used over time and have their respective advantages or disadvantages. Goh and Ang (2018) give an overview of studies implementing decomposition analyses using LMDI in recent years. Ang and Zhang (2000) and Ang (2004) assessed several IDA methods, recommending the LMDI I method due to its theoretical foundation, adaptability, ease of use and result interpretation. LMDI provides a "perfect" decomposition, i.e. not giving a residual term, which would complicate the interpretation of results. Ang et al. (2009) compare different popular decomposition methods and emphasise that for a large number of factors the advantage of simplicity of use becomes particularly evident, which is useful in our analysis.

As a common use case of IDA, the impacts of variations in overall activity level (e.g. gross value added), activity structure and energy intensity on total energy consumption in a specific sector (mostly industry) are analysed.

The additive form of LMDI approach follows this general formula:

$$
\begin{gathered}
\Delta V_{\text {tot }}=V^{T}-V^{0}=\Delta V_{x_{1}}+\Delta V_{x_{2}}+\cdots+\Delta V_{x_{n}} \\
\text { where } \Delta V_{x_{k}}=\sum_{i} L\left(V_{i}^{T}, V_{i}^{0}\right) \\
\ln \left(\frac{x_{k, i}^{T}}{x_{k, i}^{0}}\right) \text { with } L(a, b)=(a-b) /(\ln a-\ln b)
\end{gathered}
$$

Here, $V$ describes an aggregate (e.g. final energy consumption) or a sub-aggregate $i$ (e.g. an industry sector or a mode of transport) which is composed of different factors $x$ and its changes in the time period 0 to $T$ for which the decomposition is conducted (see Ang 2005). $L(a, b)$ describes the logarithmic mean of two positive real numbers - in this case, different aggregates of final energy consumption of the first 0 and last year $T-\mathrm{a}$ and $\mathrm{b}$, which are used as the weighting function in LMDI I.

The decomposition of changes in total final energy consumption FEC according to Eq. (1) can be formulated as follows:

$$
\begin{aligned}
\mathrm{FEC}^{\mathrm{T}}-\mathrm{FEC}^{0}=\Delta \mathrm{FEC}_{\text {tot }}= & \Delta \mathrm{FEC}_{\mathrm{ACT}}+\Delta \mathrm{FEC}_{\mathrm{STR}} \\
& +\Delta \mathrm{FEC}_{\mathrm{MOD}} \\
& +\Delta F \mathrm{FC}_{\mathrm{COM}} \\
& +\Delta \mathrm{FEC}_{\mathrm{HDD}} \\
& +\Delta \mathrm{FEC}_{\mathrm{EFF}}
\end{aligned}
$$

where the factor $\triangle \mathrm{FEC}_{\mathrm{ACT}}$ for the sector industry as an example would be constructed as follows (and in analogous manner for other sectors): 
$\Delta \mathrm{FEC}_{\mathrm{ACT}}=\sum_{i} L\left(\mathrm{FEC}_{i}^{T}, \mathrm{FEC}_{i}^{0}\right) \ln \left(\frac{\mathrm{ACT}_{i}^{T}}{\mathrm{ACT}_{i}^{0}}\right)$

with $\mathrm{ACT}^{T}$ and $\mathrm{ACT}^{0}$ describing the activity at a given point in time for industrial sector $i$ as defined in Eq. (1) (see Ang 2015). Furthermore, the factor $\triangle \mathrm{FEC}_{\mathrm{STR}}$ describes the changes in final energy consumption due to structural changes in industry; $\triangle \mathrm{FEC}_{\mathrm{MOD}}$ represents the changes attributed to shifting transportation modes; and $\triangle \mathrm{FEC}_{\mathrm{COM}}$ stands for changes due to variation in comfort and social factors, such as living space and inhabitants per dwelling. $\triangle \mathrm{FEC}_{\mathrm{HDD}}$ makes influences of changes in average temperatures of a country on the energy consumption for households visible, while $\triangle \mathrm{FEC}_{\mathrm{EFF}}$ provides information about the changes in final energy consumption due to improvements of energy efficiency in all sectors.

As the LMDI I method is not defined for zeros or negative numbers in the data set (due to logarithmic terms in the formulae), it is necessary to substitute these to avoid errors in computation. Two main strategies for this exist, the so-called analytic limit strategy as described by Wood and Lenzen (2006) and the small value strategy introduced by Ang and Choi (1997). The LMDI I method only results in insignificant errors if applied to a data set containing a large number of zeroes or small values. Since this is not the case for our analysis, we used the latter strategy to handle zero values and substitute those with values smaller than $10^{-20}$.

\section{Definitions}

Final energy consumption (FEC) is defined as the energy supplied to the final consumer, which is directly converted to useful energy in several end-uses, like mechanical energy or heat. It is distinguished from final consumption, which also includes non-energy uses (IEA 2004).

In this paper, we distinguish five sectors and their corresponding final energy consumption (see Fig. 2).

To compose the factors for the total final energy consumption of a country, we aggregate the factors from the sectoral level. This aggregation is depicted in Fig. 3.

In the industry sector (IND), we consider the following three underlying factors:

- Activity, which measures the changes in gross value added (GVA) of the sector (ACT)

- Structure measuring changes in the share of subsector $i$ of total gross value added $\left(\mathrm{STR}_{i}\right)$

- Energy efficiency improvement for each subsector $\left(\mathrm{INT}_{i}\right)$

Fig. 2 Schematic of analysis

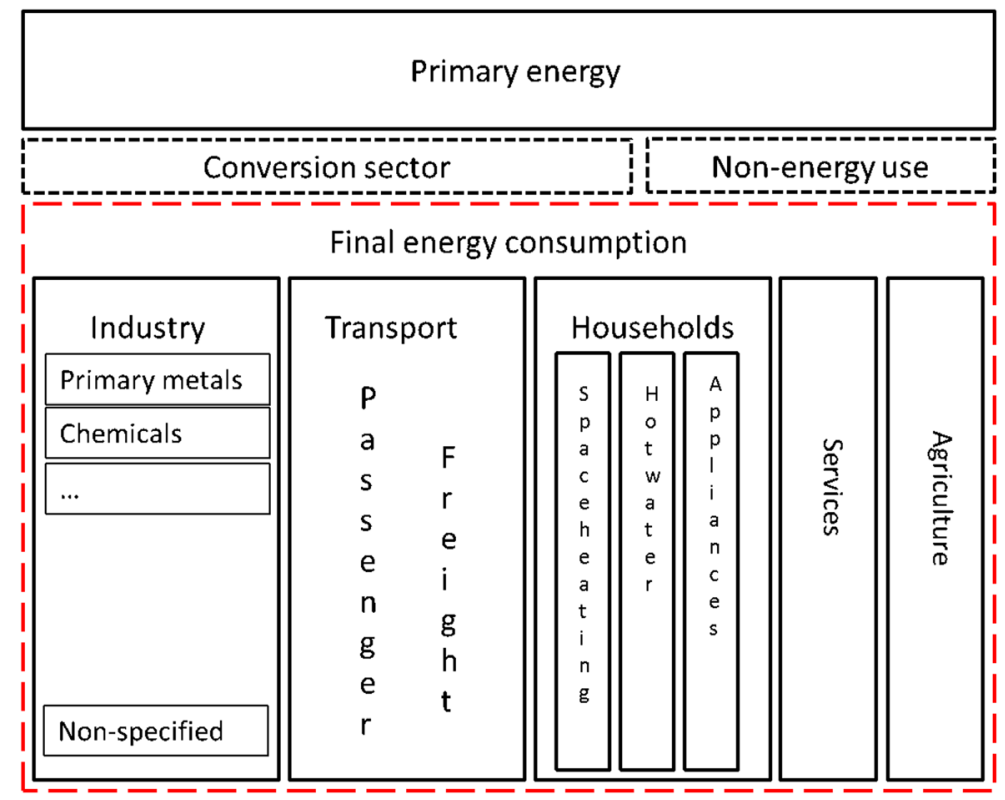




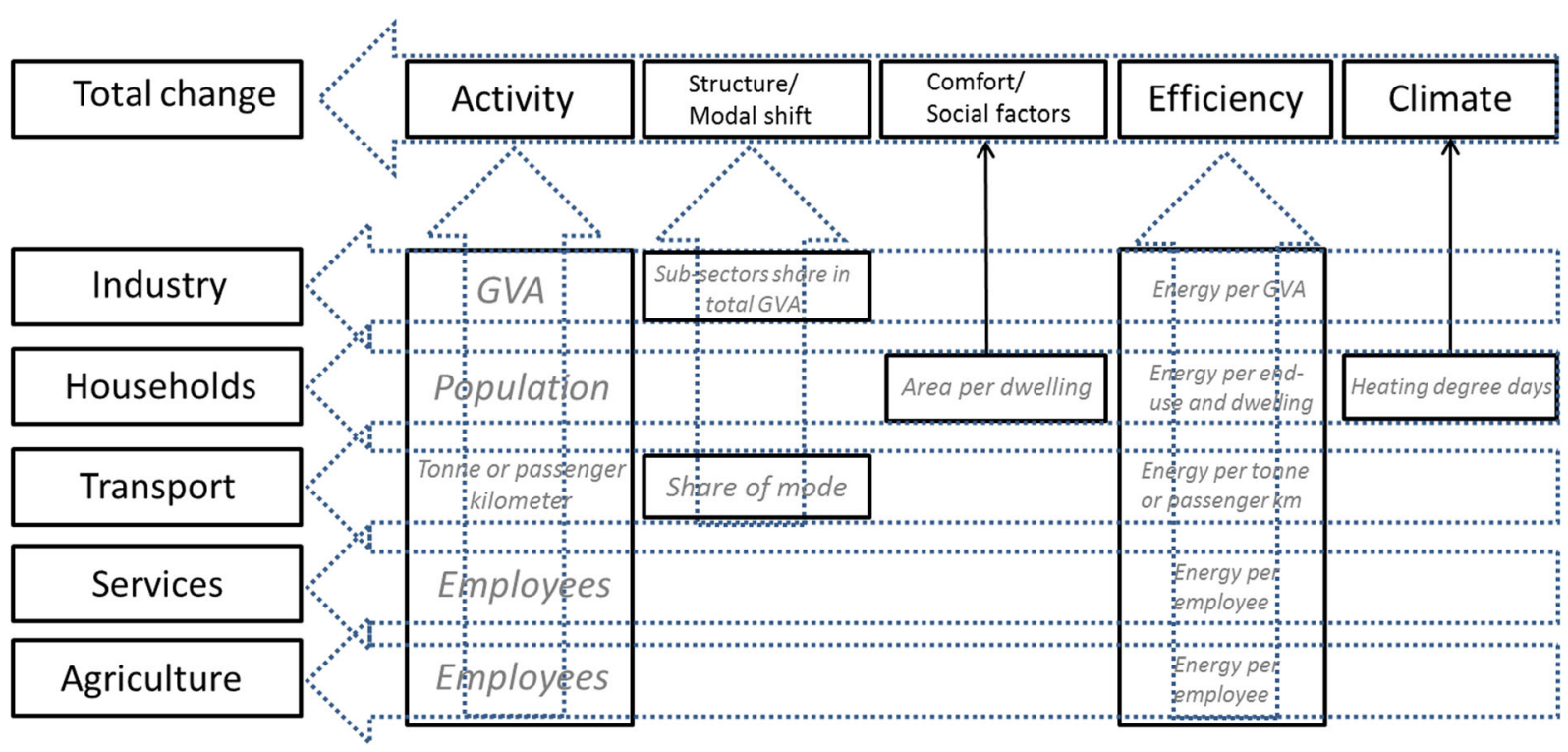

Fig. 3 Aggregation of factors over sectors (the values considered for the factors are shown in grey)

These factors are defined as follows:

$$
\begin{aligned}
\mathrm{FE}_{\mathrm{IND}} & =\sum_{i} \mathrm{ACT} \times \frac{\mathrm{ACT}_{i}}{\mathrm{ACT}} \times \frac{\mathrm{FE}_{\mathrm{IND} i}}{\mathrm{ACT}_{i}} \\
& =\sum_{i} \mathrm{ACT}_{i} \times \mathrm{STR}_{i} \times \mathrm{INT}_{i}
\end{aligned}
$$

where $i$ describes the sub-sector. In our analysis we consider the main industry sectors with their subsectors (section C in the European classification NACE for industrial activities) in Table 1, excluding sections D

Table 1 Sector and sub-sectors considered in decomposition of industry

\begin{tabular}{ll}
\hline Sub-sector & NACE rev. 2 section \\
\hline Mining and quarrying & $\mathrm{B}$ \\
Manufacturing industry & $\mathrm{C}$ \\
Primary metals & 24 \\
Chemicals and petrochemicals & 20,21 \\
Non-metallic minerals & 23 \\
Food and tobacco & $10,11,12$ \\
Textile and leather & $13,14,15$ \\
Paper, pulp and print & 17,18 \\
Transport equipment & 29,30 \\
Machinery & 28 \\
Wood and wood products & 16 \\
Non-specified (industry) & 32 \\
Construction & F \\
\hline
\end{tabular}

(electricity, gas, steam and air-conditioning supply) and E (water supply, sewerage, waste management and remediation).

For the sector "households" $(\mathrm{HH})$, the approach is designed based on final energy uses in that sector. In total, we consider up to five different factors, depending on the end-use, which are shown in Table 2.

For each of the following end-uses, a separate formula is used for the decomposition:

\section{- Space heating}

$$
\begin{aligned}
\mathrm{FE}_{\mathrm{HH}_{\mathrm{SH}}=} & \mathrm{ACT} \times \frac{\mathrm{DWE}}{\mathrm{ACT}} \times \frac{\mathrm{ARE}}{\mathrm{DWE}} \times \frac{\mathrm{FE}_{\mathrm{HH}_{\mathrm{SH}}}}{A R E} \\
& \times \frac{\mathrm{HDD}_{\text {present }}}{\mathrm{HDD} \mathrm{D}_{\text {long-term }}} \\
= & \mathrm{ACT} \times \mathrm{SOC} \times \mathrm{COM} \times \mathrm{INT} \times \mathrm{CLI}
\end{aligned}
$$

- Hot water

$$
\mathrm{FE}_{\mathrm{HH}}=\mathrm{ACT} \times \frac{\mathrm{FE}_{\mathrm{HH}}}{\mathrm{ACT}}=\mathrm{ACT} \times \mathrm{INT}
$$


Table 2 Factors of decomposition in the sector households

\begin{tabular}{|c|c|c|c|c|}
\hline Factor & Space heating & Hot water & Cooking & Electric appliances/lighting \\
\hline Activity & Population & Population & Population & Population \\
\hline Social factors & Dwellings per population & - & $\begin{array}{l}\text { Dwellings per } \\
\text { population }\end{array}$ & Dwellings per population \\
\hline Comfort/behaviour & Area per dwelling & - & - & - \\
\hline Energy efficiency & $\begin{array}{l}\text { Final energy consumption for } \\
\text { space heating per } \mathrm{m}^{2} \text { of } \\
\text { dwelling }\end{array}$ & $\begin{array}{l}\text { Final energy } \\
\text { consumption for hot } \\
\text { water per capita }\end{array}$ & $\begin{array}{l}\text { Final energy } \\
\text { consumption for } \\
\text { cooking per dwelling }\end{array}$ & $\begin{array}{l}\text { Final energy consumption for } \\
\text { electric appliances/lighting per } \\
\text { dwelling }\end{array}$ \\
\hline $\begin{array}{l}\text { Annual climate } \\
\text { variation }\end{array}$ & $\begin{array}{l}\text { Heating degree days (HDD) } \\
\text { normalised to long-term } \\
\text { HDD }\end{array}$ & - & - & - \\
\hline
\end{tabular}

\section{- Cooking}

$$
\begin{aligned}
\mathrm{FE}_{\mathrm{HH}_{\mathrm{CK}}} & =\mathrm{ACT} \times \frac{\mathrm{DWE}}{\mathrm{ACT}} \times \frac{\mathrm{FE}_{\mathrm{HH}_{\mathrm{CK}}}}{\mathrm{DWE}} \\
& =\mathrm{ACT} \times \mathrm{SOC} \times \mathrm{INT}
\end{aligned}
$$

- Electric appliances and lighting

$$
\begin{aligned}
\mathrm{FE}_{\mathrm{HH}_{\mathrm{AP}}} & =\mathrm{ACT} \times \frac{\mathrm{DWE}}{\mathrm{ACT}} \times \frac{\mathrm{FE}_{\mathrm{HH}_{\mathrm{AP}}}}{\mathrm{DWE}} \\
& =\mathrm{ACT} \times \mathrm{SOC} \times \mathrm{INT}
\end{aligned}
$$

where the factor ACT measures the impact of population on the changes of final energy consumption. SOC (defined as dwellings per capita) shows influence of household size (persons per dwelling) on energy consumption, while the factor COM shows the influence of the size of dwellings, i.e. comfort of living. The factors INT and CLI measure the influence of changes in efficiency in households and the impact of changes in weather on the space heating consumption. For the latter effect, see more the more detailed discussion further on.

For the total sector households, the different factor on the end-use level are aggregated as shown in Fig. 4.

The final energy consumption of the sector transport is composed of the factors activity, modal shift and energy efficiency. These are calculated

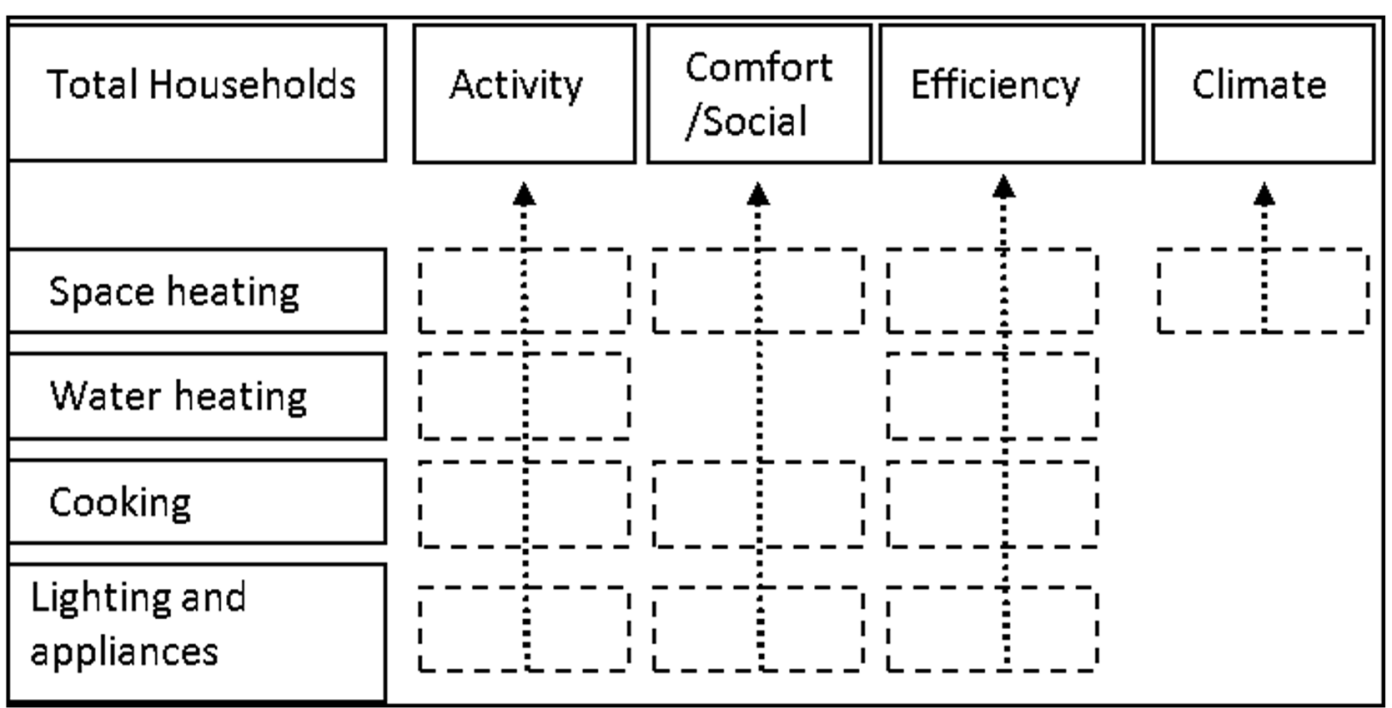

Fig. 4 Aggregation of factors in the sector households 
separately for passenger and freight transport using the following formulae:

- Passenger transport

$$
\begin{aligned}
\mathrm{FE}_{\text {Pass }} & =\sum_{i} \mathrm{ACT} \times \frac{\mathrm{ACT}_{i}}{\mathrm{ACT}} \times \frac{\mathrm{FE}_{\text {Pass }, i}}{\mathrm{ACT}_{i}} \\
& =\sum_{i} \mathrm{ACT}_{\mathrm{i}} \times \mathrm{MOD}_{i} \times \mathrm{INT}_{i}
\end{aligned}
$$

- Freight transport

$$
\begin{aligned}
\mathrm{FE}_{\text {Goods }} & =\sum_{i} \mathrm{ACT} \times \frac{\mathrm{ACT}_{i}}{\mathrm{ACT}} \times \frac{\mathrm{FE}_{\mathrm{Goods}, i}}{\mathrm{ACT}_{i}} \\
& =\sum_{i} \mathrm{ACT}_{i} \times \mathrm{MOD}_{i} \times \mathrm{INT}_{i}
\end{aligned}
$$

where the factors $\mathrm{ACT}$ and $\mathrm{ACT}_{i}$ show the impact of changes in transport performance measured in passenger or tonne-kilometres of a transport mode $i$ (i.e. road, rail) or overall. MOD describes the changes due to modal shift, i.e. the switch from or to road transport such as cars and lorries. $\mathrm{INT}_{i}$ gives information on the changes in energy efficiency, i.e. energy consumption per passenger or tonnekilometre of a mode $i$. These factors are analysed for both freight and passenger transport.

For the sectors services (SER) as well as "agriculture, fishing + other" (AGR), the final energy consumption is decomposed into two factors, the effect of the number of employees and of energy efficiency (specific energy consumption per employee) (see Formula 11). For the service sector, despite its importance, there is no coherent data set on energy end-uses available covering the whole of the European Union. Thus, a factor showing the influences of the climate unfortunately is not available for the sector services.

$\mathrm{FE}_{\mathrm{SER} / \mathrm{AGR}}=\mathrm{ACT} \times \frac{\mathrm{FE}_{\frac{\mathrm{SER}}{\mathrm{AGR}}}}{\mathrm{ACT}}=\mathrm{ACT} \times \mathrm{INT}$
Data sources

To obtain detailed insight into the effects of each sector and thus allow more in-depth analysis, we use a combination of three data sources, namely the ODYSSEE database $^{1}$, Eurostat and the statistical pocketbook by DG TREN (European Commission 2016b).

For the energy demand data, we used publicly accessible data for the EU28 and its member states from the European Central Statistical Office Eurostat. Our database was compiled with bulk data from the tables "Simplified energy balances" (table code nrg100a), "Supply, transformation and consumption of electricity" (nrg105a) and "Supply, transformation and consumption of heat" (nrg106a). ${ }^{2}$

Eurostat data are, however, not detailed enough to carry out the analysis at a sufficient level of depth. We therefore for this analysis further used data compiled by the ODYSSEE-MURE project (ODYSSEE-MURE 2017) for the aspects listed in Table 3.

For some special data series on transport, we also used data from the statistical pocketbook of the Directorate General for Mobility and Transport (DG TREN ${ }^{3}$ ).

\section{Data gaps and imputation}

There were a few missing data points in the ODYSSEE data. Those were filled with other data source such as national balances, DG TREN or Eurostat data, where suitable. Most countries are covered by the ODYSSEE database to a large degree. For a small number of countries, the data on gross value added for the year 2015 was not completely available from neither Eurostat nor ODYSSEE, which is why these gaps are filled with the help of production indices, as they reflect economic activity sufficiently accurately.

For Malta and Luxembourg, data show several gaps in a significant number of data series. For this reason, and since those member states do not significantly contribute to the consumption of energy in the European Union, we omitted them in our analysis. Also, an extensive data imputation is always a source of error and can heavily affect the results of the analyses for individual countries.

\footnotetext{
${ }^{1} \mathrm{http}: / /$ www.odyssee-mure.eu

$2 \mathrm{http} / / / \mathrm{ec}$.europa.eu/eurostat/data/database

${ }^{3} \mathrm{http}: / /$ ec.europa.eu/transport/facts-fundings/statistics/
} 
Table 3 Data used in different sectors originating from the ODYSSEE-MURE database (ODYSSEE-MURE 2017)

\begin{tabular}{ll}
\hline Sector & Data \\
\hline $\begin{array}{l}\text { Industry } \\
\text { Households }\end{array}$ & $\begin{array}{l}\text { Gross value added } \\
\text { Number of households, average population, number } \\
\text { of dwellings, share of end-uses, heating degree } \\
\text { days }\end{array}$ \\
Transport & $\begin{array}{r}\text { Passenger-kilometres of passenger traffic per mode } \\
\text { (road, rail, air traffic) tonne-kilometre for freight } \\
\text { traffic per mode, energy consumption per mode }\end{array}$ \\
Services & $\begin{array}{l}\text { Number of employees } \\
\text { Agriculture }\end{array}$ \\
\hline
\end{tabular}

\section{Correction of annual climate/weather conditions}

While effects of changes in annual average temperature play a minor role in sectors like industry and transport, energy consumption of households and services is highly influenced by climate and changes in weather. To account for the influence on final energy consumption by temperature, we demarcate an own effect in the households sector as "annual climate variation (weather)". This effect links the changes in heating degree days to the share of change in final energy consumption in the respective sector. For the service sector, this correction could not be made as there is no reliable breakdown of end-uses available for all countries.

\section{Results}

While the analysis was carried out for the European Union as a whole and most of its member states (except Malta and Luxembourg), we will here additionally focus on two countries besides the EU28. We selected Germany and Poland for a detailed comparison, as they represent good examples of countries whose energy consumption is developing on different levels of advancement towards the European Union target. Germany represents a country where the final energy consumption has reached a certain saturation level (variation of $\pm 6 \%$ within the last 15 years) and economic activity shows a steady growth. At the same time, Germany's final energy consumption still did not reach the target of 194.3 Mtoe proposed by Germany in the context of the EED for 2020 and faces a gap of $9.4 \%$. On the other hand, Poland represents a state which is still expected to enjoy strong economic growth and has never exceeded its 2020 target proposed in the frame of the EED. Furthermore, Poland shows large potential of gains in energy efficiency in industry and other sectors, while Germany's most energy-intensive sector industry partially reached a saturation of process efficiency in recent years.

Results for all member states and the European Union are shown in Table 4 (Appendix).

\section{Results for the European Union}

Total final energy consumption in the European Union declined by about 48 Mtoe in the time period 2000 to 2015 (see Fig. 5). Most of this reduction was realised in the sector industry with -59 Mtoe. This trend was counteracted by the developments in transport (+ 14 Mtoe) and services (+ 17 Mtoe). The households sector contributed with a reduction of final energy consumption of 16 Mtoe.

Activity levels of the various sectors accounted for the largest increase of about 125 Mtoe, followed by changes from comfort/behaviour, social factors and climate effects in household consumption, which contributed 35 Mtoe and 6 Mtoe, respectively. Modal shift in transport had only a minor increasing effect of about 2.6 Mtoe. The main decreasing effect - counteracting all of the increasing effects - is contributed by efficiency gains in all sectors with 210 Mtoe. Structural changes contributed in a minor manner to the decrease with 6.6 Mtoe. The main share of the efficiency gains occurred in industry (85 Mtoe) and households ( -69 Mtoe), followed by transport ( -43 Mtoe) and others ( -12 Mtoe) (see Fig. 5).

While comfort and behavioural effects in households, driven by the size of dwellings and persons per dwelling, had an increasing effect on energy consumption, improved efficiency, i.e. lower energy consumption for space heating per square meter of dwelling area, had a major reducing impact of -59 Mtoe, while the total efficiency gains in households (including appliances) had an impact of -69 Mtoe. These efficiency gains were mainly realised through more efficient space heating technologies and retrofitting of building envelopes decreasing the specific consumption by about $30 \%$ in the period of 2000 to 2015 resulting in a strong reduction of final energy consumption. This is largely due to the EPBD and its national implementations in performance standards. Retrofit schemes also have a large impact on the specific energy consumption of buildings (Webber et al. 2015). The efficiency gains in electric appliances in total played only a minor role, 


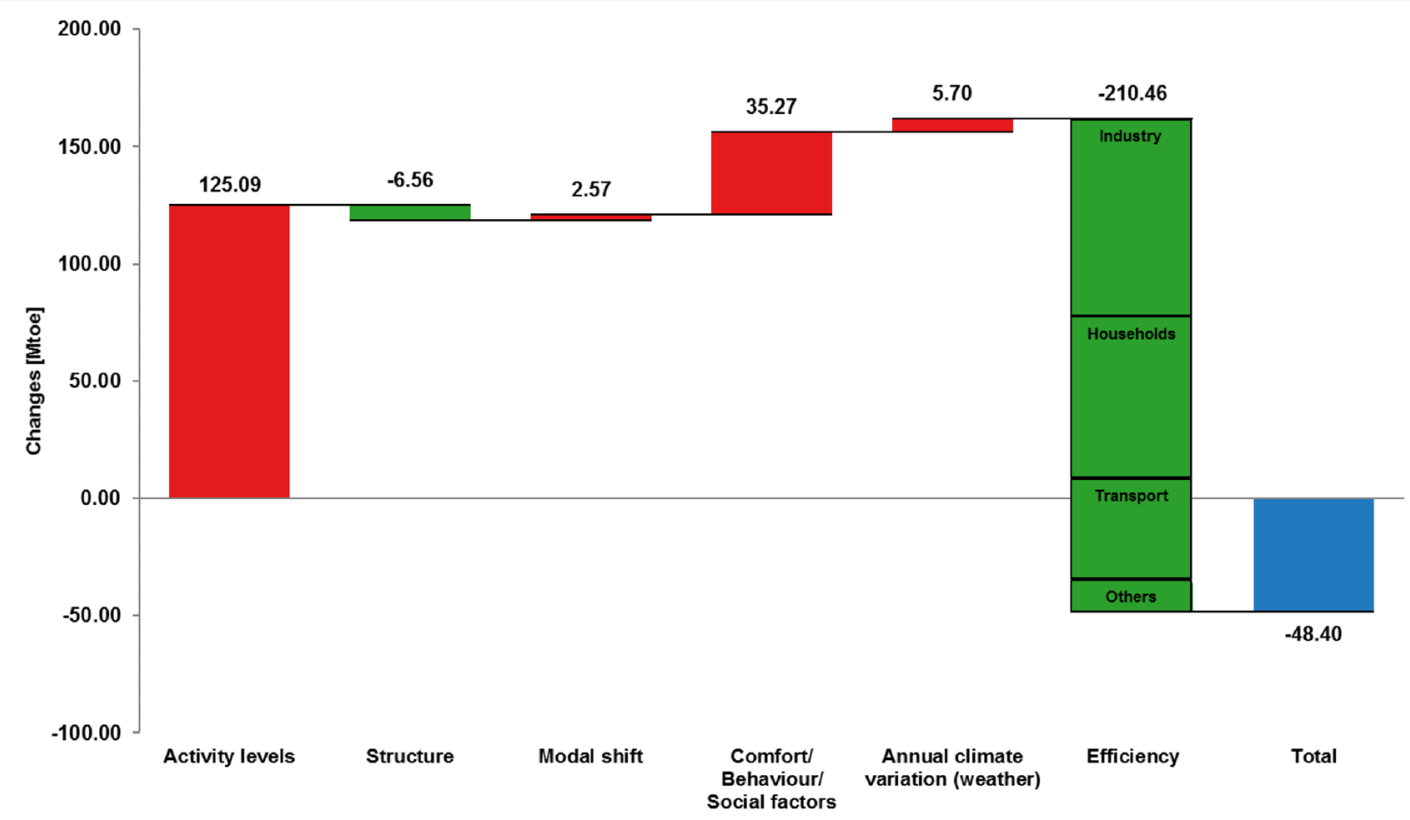

Fig. 5 Factors contributing to the change in total energy consumption in EU28 from 2000 to 2015

despite strong policy efforts such as Labelling and Ecodesign. This can be attributed to increasing numbers of appliances, i.e. rising rates of ownership as well as additional small appliances, in households counteracting the savings achieved by efficiency improvements. Compared to these effects, the increase of the EU's population by $4 \%$ resulted in a comparatively small increase of +12 Mtoe.
The comfort/behaviour/social factors and the weather factor had a strong increasing effect, with 35 and 6 Mtoe, respectively. The comfort effect is most pronounced for the end-use of space heating as it is directly coupled to the increase of dwelling size, which grew by over $6 \%$ in the EU from 2000 to 2015. Overall, the combined effects led to a decrease of final energy consumption by 16 Mtoe in households (see Fig. 6).

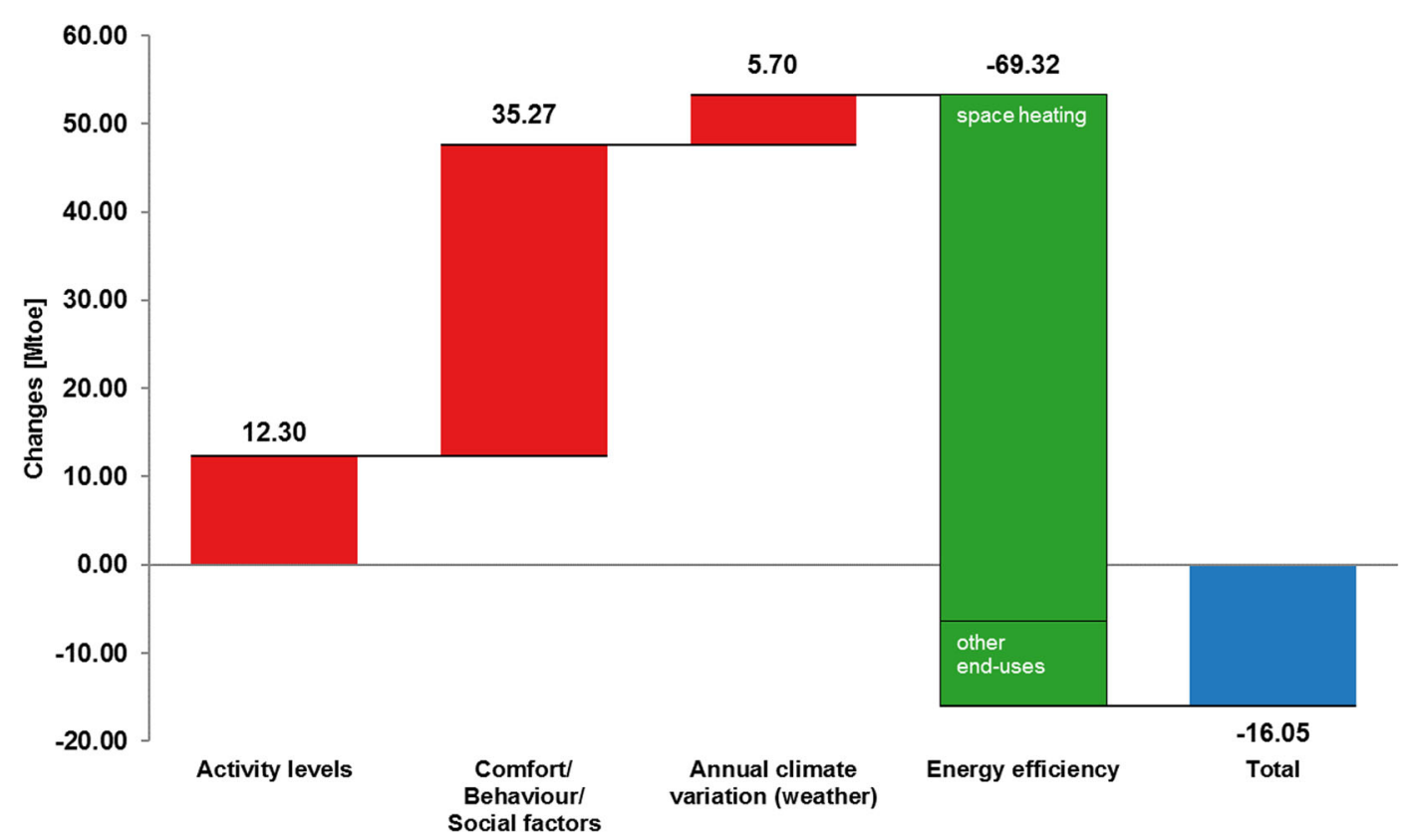

Fig. 6 Changes in final energy consumption of households (EU28, 2000 to 2015) 


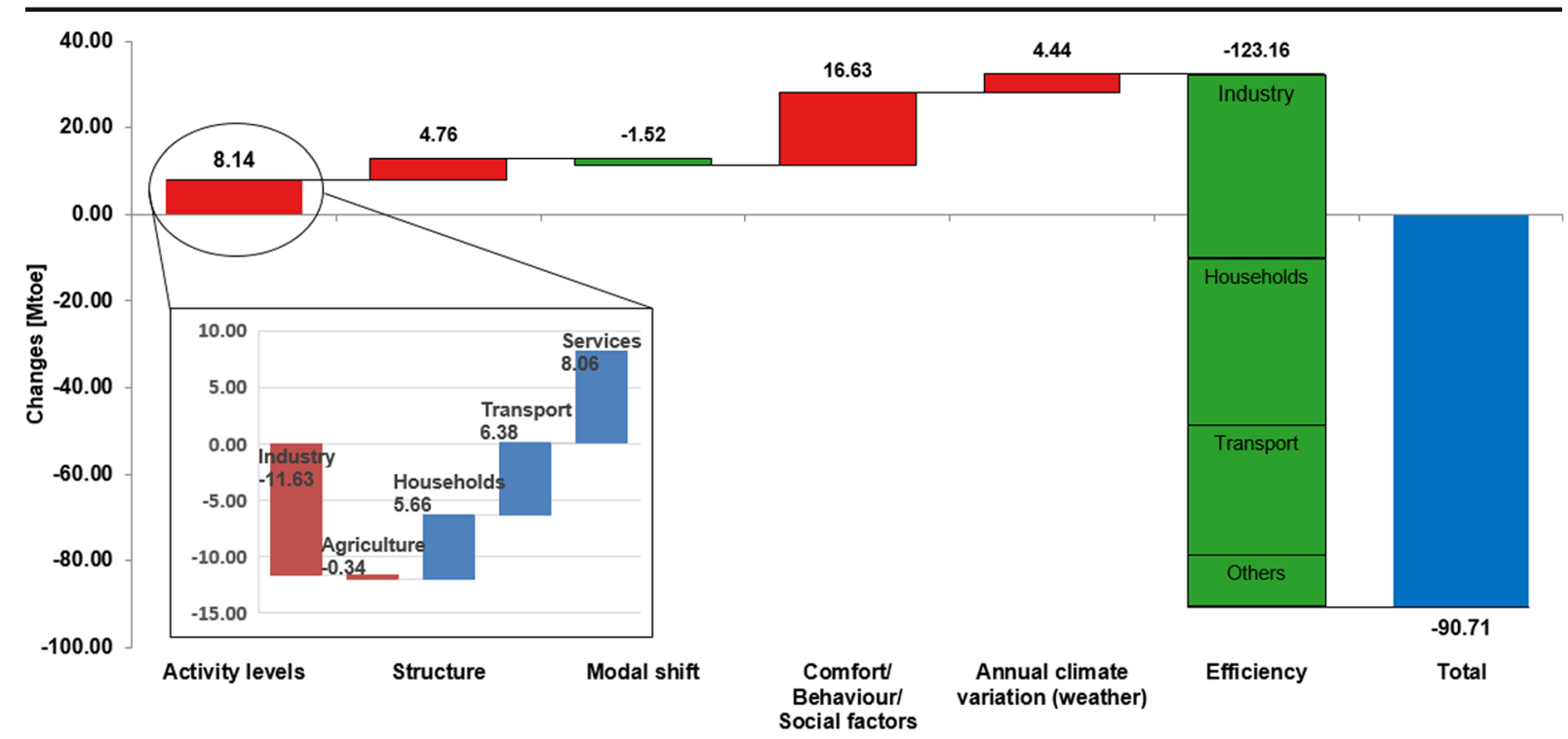

Fig. 7 Factors contributing to the change in total energy consumption in EU28 from 2007 to 2015

In the period from 2007 to 2015 , i.e. the time of and direct aftermath of the economic crisis, activity had a much smaller positive impact on final energy consumption compared to the period of 2000 to 2015 as economic activity in industry dropped drastically. This led to a decreased activity impact of industry of almost 12 Mtoe, which compensated for approximately half of the increase related to rising activity in other sectors (see Fig. 7).
In industry, the increase in activity, expressed by gross value added had an increasing impact on energy consumption of 33 Mtoe. Structural changes in the sector industry, i.e. changes of the composition of the sector across the different sub-sectors led to a decreasing effect of around 6.6 Mtoe (see Fig. 8). Efficiency gains in the sector resulted in a decrease of 85 Mtoe dominating all other effects. Overall, the sector industry played a

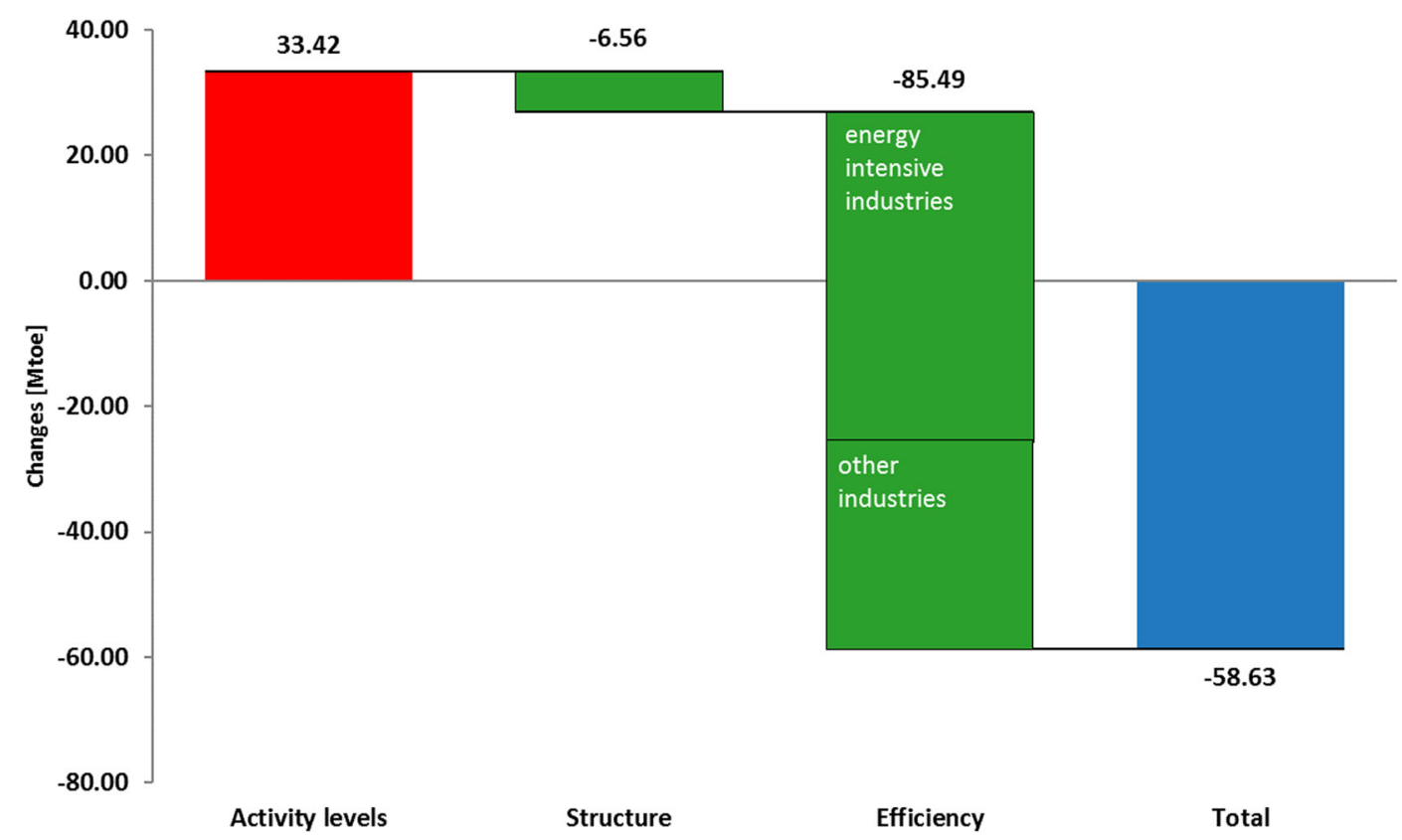

Fig. 8 Changes in final energy consumption of industry (EU28, 2000 to 2015) (Energy intensive industries include the sub-sectors "primary metals", "paper and pulp", "chemical and petrochemical" and "textile and leather") 
major role in the reduction of final energy consumption in the EU28 with a reduction of its total final energy consumption by almost $18 \%$ between 2000 and 2015 . The main share of the efficiency gains was realised in the sub-sectors "primary metals" $(-23.9$ Mtoe $)$ and "chemical and petrochemical" (-24.2 Mtoe).

Besides autonomous progress in energy efficiency, this can be assumed to be the result of successful policies both at the European and at the national level. Particularly, the Emission Trading Scheme, the Ecodesign and Labelling Directive as well as the introduction of energy audits and energy management systems as result of the EED are likely to have played an important role at the European level. In addition, it is plausible to assume that national programs like the subsidy programme on energy efficient cross-cutting technologies as part of the National Action Plan on Energy Efficiency (NAPE) in Germany had a considerable impact on energy efficiency at the national level.

In the transport sector, total final energy consumption decreased by 14 Mtoe between 2000 and 2015 (see Fig. 9). This total change is composed of an increasing effect of almost 55 Mtoe due to rising activity levels in passenger transport (passenger-kilometres $+8 \%$ ) as well as freight transport (tonne-kilometres $+9 \%$ ), modal shift towards more road-based traffic (+2.6 Mtoe) and energy efficiency $(-43.3$ Mtoe). This shows that public policies promoting modal shift so far had at best the impact to slow down the trends towards road-based transport. The modal shift mainly occurred in freight transport, where a slight shift from rail transport to road transport took place. Gains in energy efficiency in passenger transport mainly occurred in rail bound traffic by decreasing specific consumption by $30 \%$, while specific consumption in road passenger transport decreased by only $8 \%$ in the same period. These efficiency improvements resulted in -1.14 Mtoe (rail) and -16 Mtoe (road). This indicates that European transport policies aiming at technological improvements, such as $\mathrm{CO}_{2}$ standards for cars and vans, car labelling, as well as national policies such as bonus/malus schemes in France, had some impact in the period considered, but not yet enough to curb the transport need (Ministère de la Transition écologique et solidaire 2018).

Compared to the period 2000-2015, the energy efficiency in transport played a bigger role in the period of 2007 to 2015 and outpaced all other factors (see Fig. 10) resulting in a total change of -25 Mtoe. A relatively small rise in activity had an effect of about +6 Mtoe, while modal shift had a reducing effect of 1.5 Mtoe.

The changes of the service sector are mainly driven by rising activity levels (number of employees): plus $19 \%$ regarding the number of employees. This resulted in an increasing effect of almost 25 Mtoe. In comparison, energy efficiency in this sector played only a minor role, with a decrease by 8 Mtoe in the time period from 2000 to 2015 . This changed in the period after 2007, where energy efficiency improved more strongly in the service sector, resulting in a decrease of energy consumption per employee by almost $1.5 \%$.

Overall, the final energy consumption in the service sector in the EU28 rose by almost 17 Mtoe from 2000 to 2015. However, this development was different in the period of 2007 to 2015 as the final energy consumption of the service sector dropped by about 2.2 Mtoe (see Fig. 11). This difference in development from 2007 to

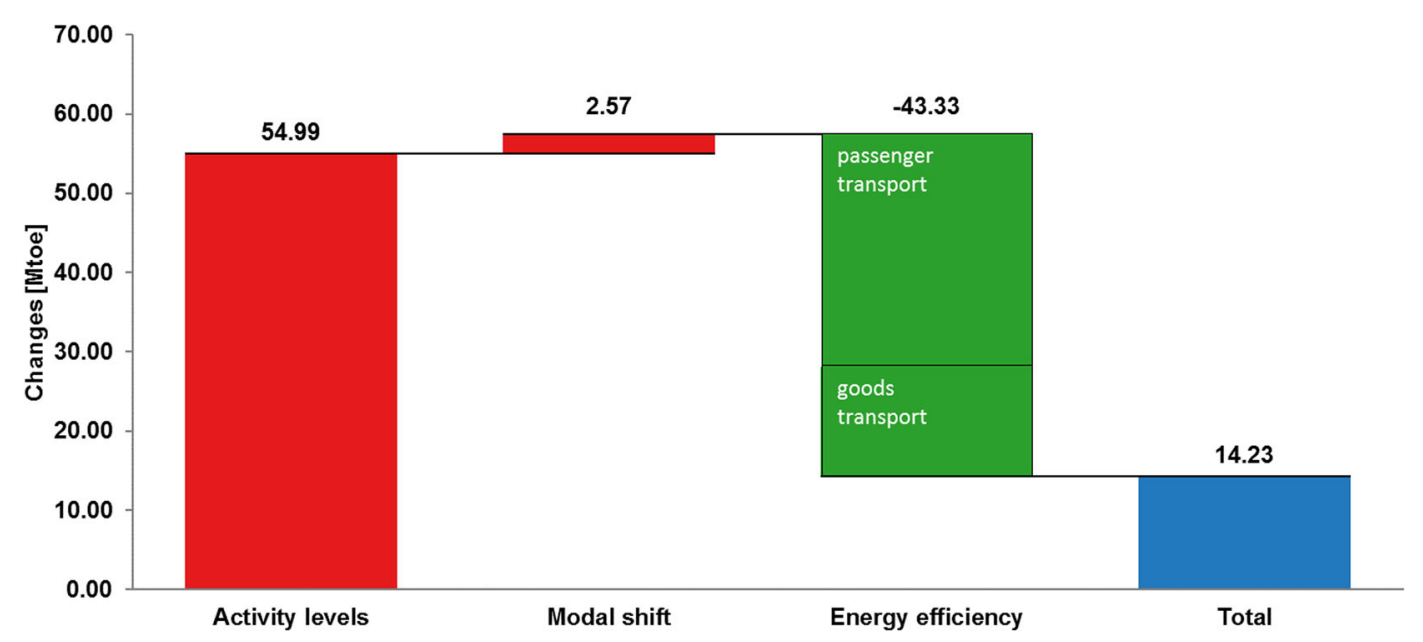

Fig. 9 Changes in final energy consumption of transport (EU28, 2000 to 2015) 


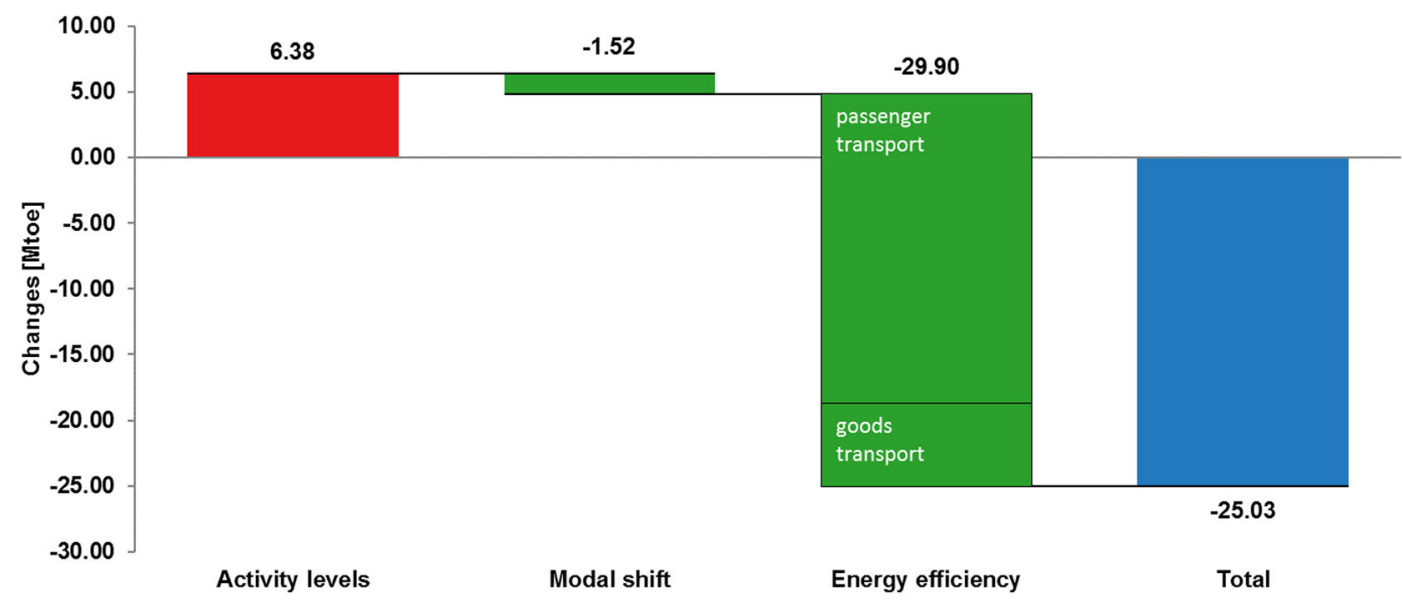

Fig. 10 Changes in final energy consumption of transport (EU28, 2007 to 2015)

2015 can be assumed to be mainly related to the introduction of policies regarding energy efficiency in buildings and the Ecodesign Directive affecting energy efficiency in technologies used in the service sector.

In agriculture, the activity levels stayed almost constant ( $-0.6 \%$ from 2000 to 2015), resulting in a small decrease of below 0.2 Mtoe. Energy efficiency gains in this sector resulted in a decreasing effect of 4.4 Mtoe. Overall, the final energy consumption in the sector dropped by 4.6 Mtoe from 2000 to 2015 (see Fig. 12).

Results for Germany and Poland

As discussed above, the changes in final energy consumption at the European Union level were primarily driven by energy efficiency improvements in the industry sector followed by households.

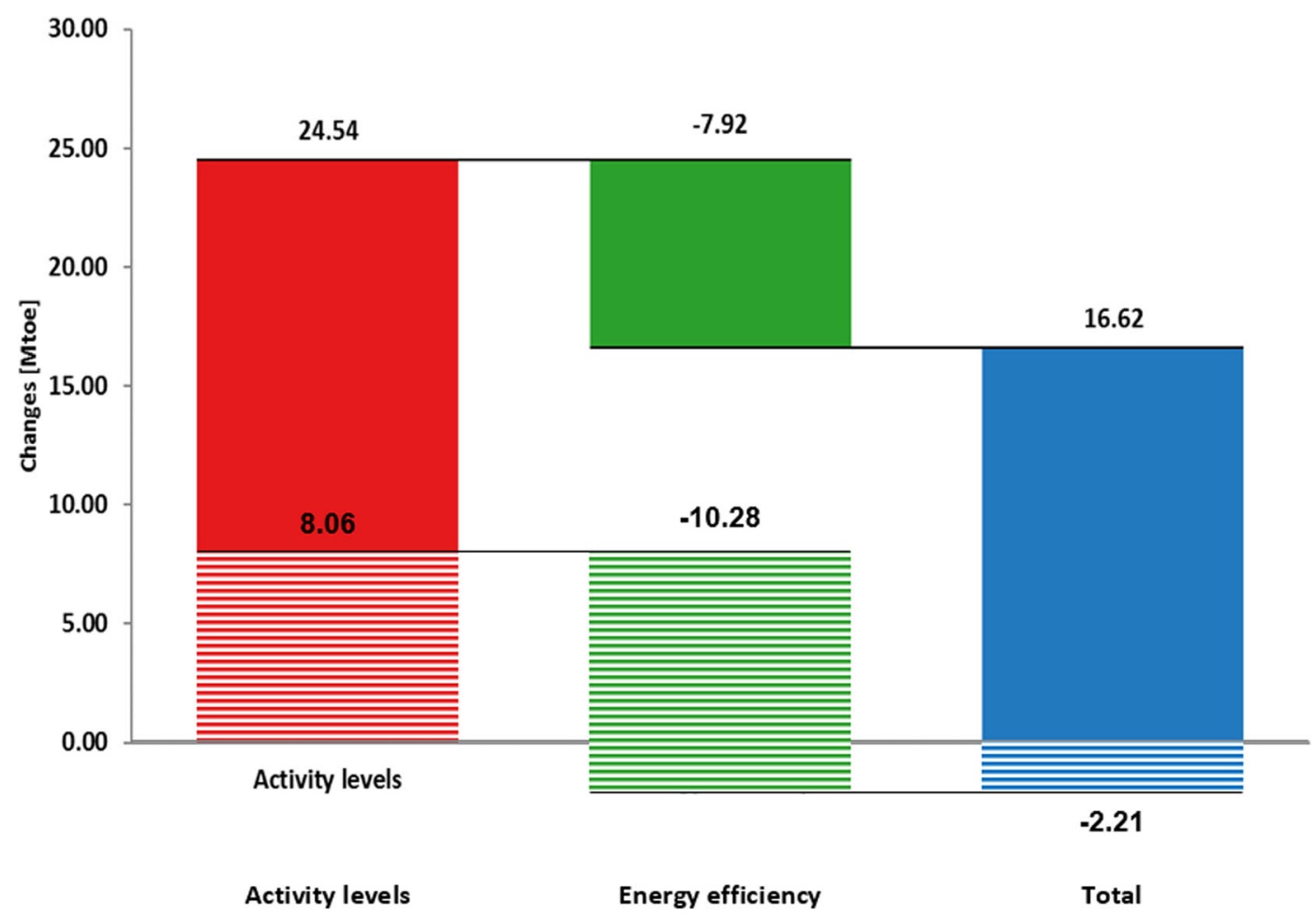

Fig. 11 Changes in final energy consumption of the service sector (EU28, 2000 to 2015 and 2007 to 2015-striped) 


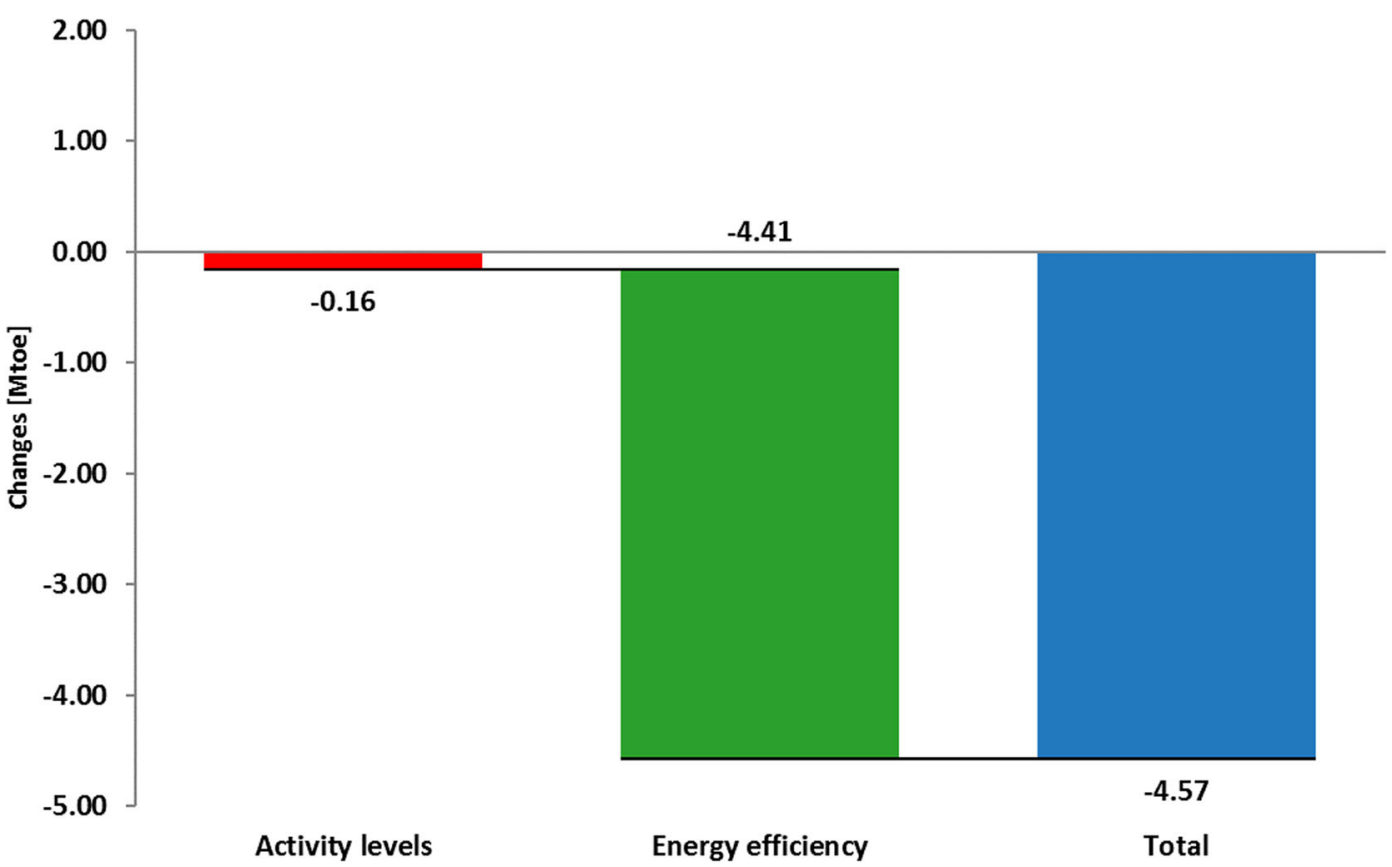

Fig. 12 Changes in final energy consumption of agriculture (EU28, 2000 to 2015)

As an in-detail comparative example, we here show the results for two countries. On the one hand, Germany, as a representative for countries in the EU which have reached a certain saturation level regarding their energy consumption. On the other hand, Poland, which stands for new member states of the EU, which are expected to show significant economic growth and thus increasing energy consumption in the future.

The changes in final energy consumption in Germany are mainly driven by energy efficiency gains of almost
38 Mtoe in the period 2000-2015 (Fig. 13). These were counteracted by rising activity levels causing an increase of 26 Mtoe. Comfort/behaviour and social factors in the residential sector contributed an increase of around 7 Mtoe, while climate variation is found to contribute an increase of almost 2 Mtoe. Modal shift in the transport sector only had a small effect of below 1 Mtoe on the change in final energy consumption.

The changes in the period of 2007 to 2015 show a similar picture. However, due to smaller energy

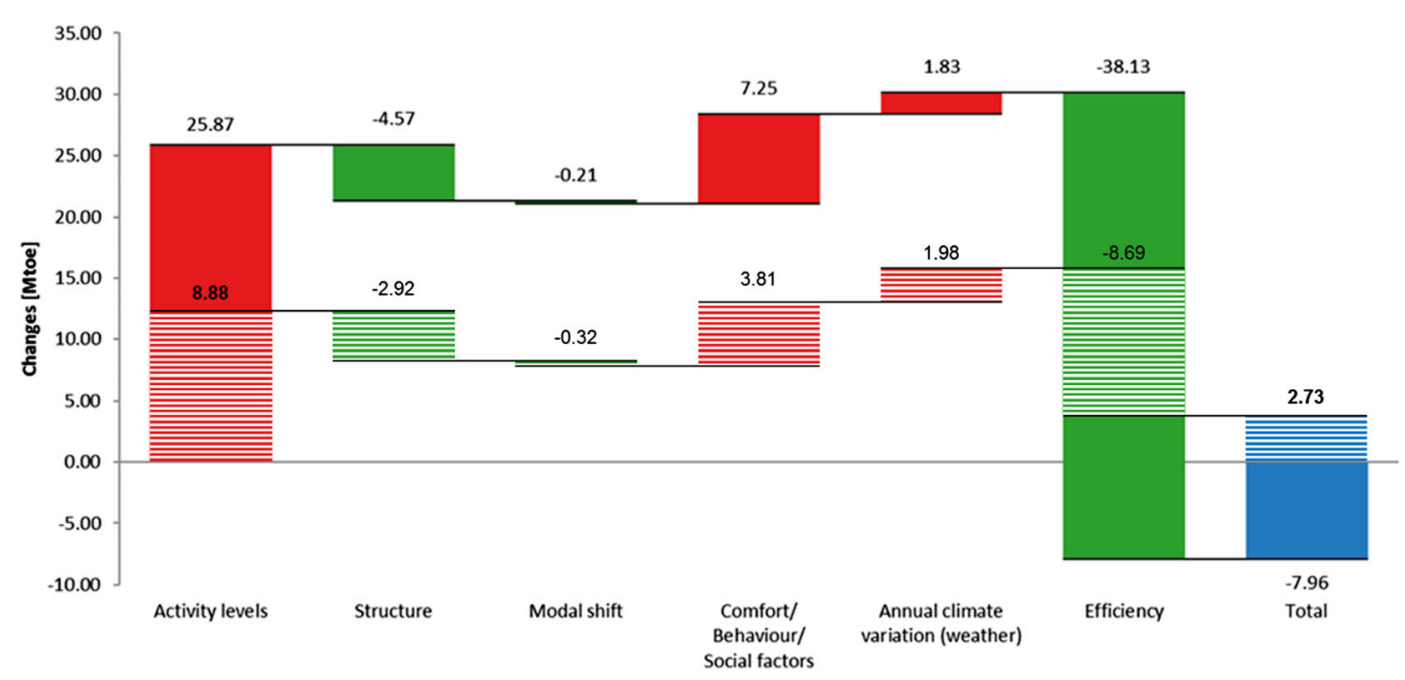

Fig.13 Changes in total final energy consumption in (Germany, 2000 to 2015 and 2007 to 2015 - striped) 


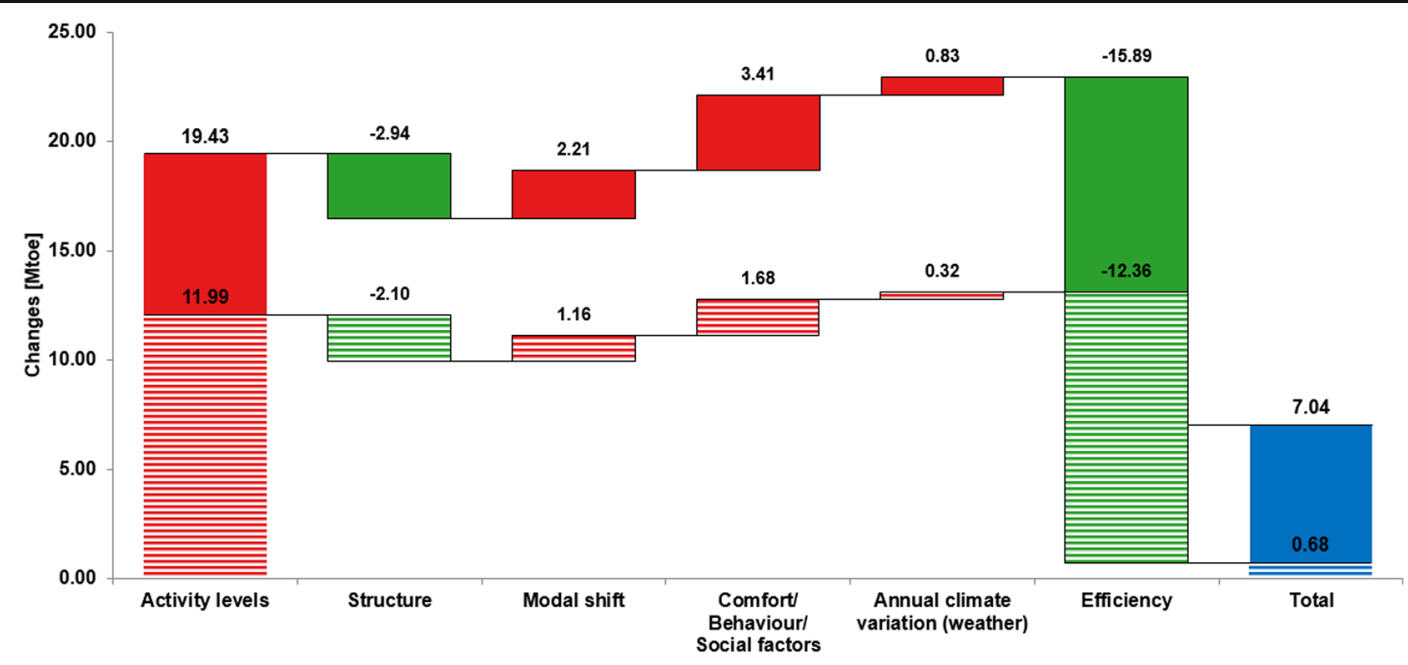

Fig. 14 Changes in total final energy consumption (Poland, 2000 to 2015 and 2007 to 2015 - striped)

efficiency gains $(-8.7$ Mtoe) in this period, the total change resulted in a slight increase of 2.7 Mtoe.

Poland's final energy consumption underwent similar changes to Germany's in the period considered (Fig. 14). Activity changes amounted to a total increase of 19 Mtoe and were only slightly smaller than in Germany, while Poland's final energy consumption represents only one third of Germany's. These increasing activities occurred mainly in industry and in transport. Structural changes in industry reduced total final consumption by about 3 Mtoe. Modal shift had a larger impact compared to Germany with about 2 Mtoe (i.e. a much stronger shift to roadbased transport). Comfort/behavioural and social factors (i.e. increase in persons and area per dwelling) had an effect of +3 Mtoe. Changes in climate/weather had a more marginal effect, resulting in an increase of less than 1 Mtoe. Increasing energy efficiency had one of the biggest impacts with almost -16 Mtoe.

In the time period of 2000 to 2015, the gross value added of Germany's industry increased by about $20 \%$. This rising activity of industry had an increasing effect of nearly 11 Mtoe (see Fig. 15)

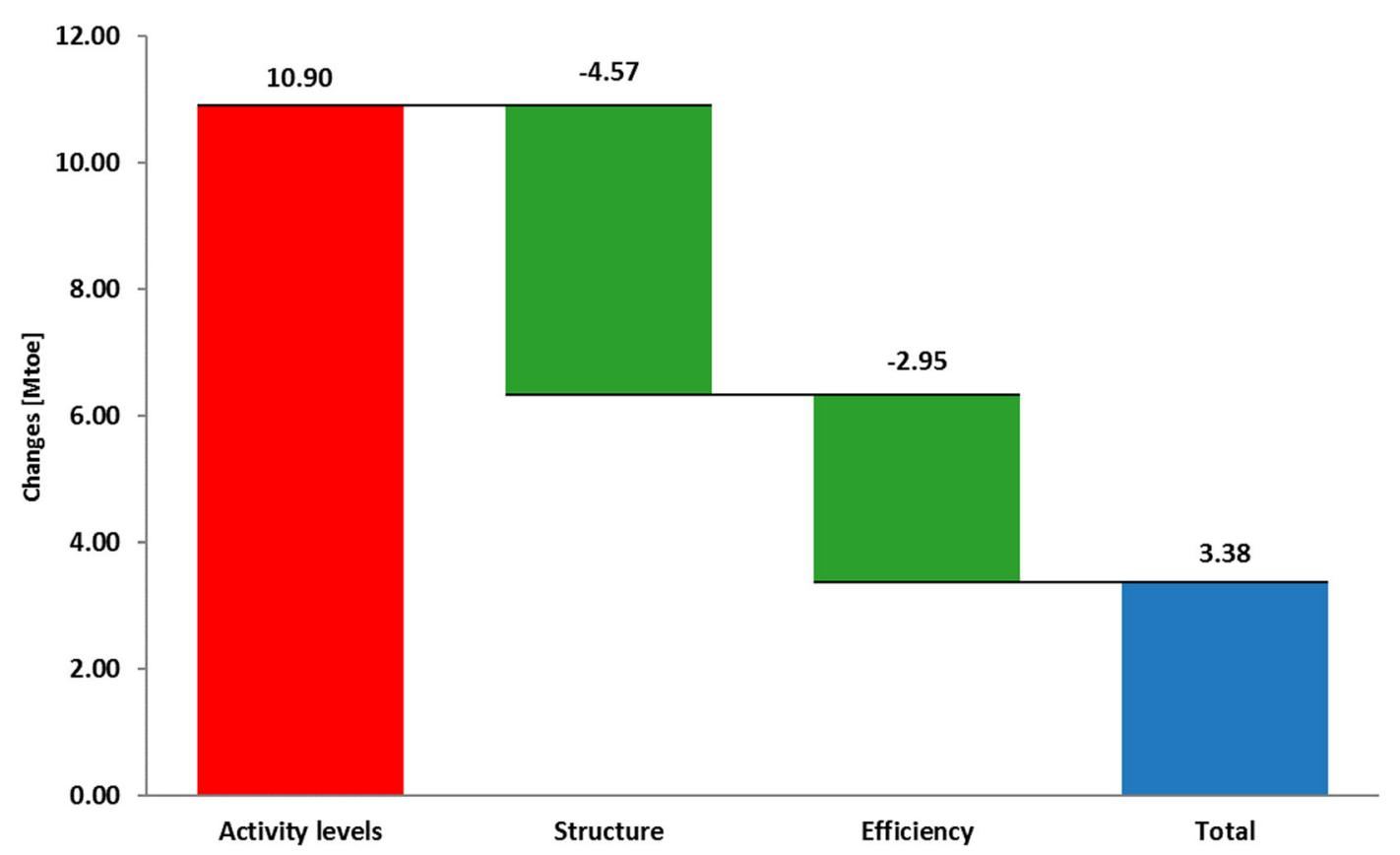

Fig. 15 Changes in final energy consumption of industry (Germany, 2000 to 2015) 
and was mostly realised in the sub-sectors "transport equipment" (+83\% GVA from 2000 to 2015) and "chemical and petrochemical" (+32\%). Structural changes in the sector towards less energy intensive sub-sectors mainly at the expense of the sub-sectors "primary metals" and "non-metallic minerals" reduced final consumption by about 5 Mtoe. An increase of $14 \%$ in overall efficiency in industry resulted in a decrease of 3 Mtoe. These gains in energy efficiency mainly were realised in the sub-sectors "transport equipment" and "primary metals". In primary metals, this was partly due to a shift towards more recycled steel. All these effects combined led to an increase of final energy consumption by 3.4 Mtoe. This contrasts with the development at the EU level where industry contributed most to the efficiency gains.

Poland's industry increased its gross value added by $83 \%$ in the time period considered. This resulted in an increasing activity effect of about 10 Mtoe (see Fig. 16). Structural changes decreased final energy consumption by 3 Mtoe, while the energy efficiency gains contributed with a reduction of almost 11 Mtoe. These gains were mainly realised in the sub-sectors "chemical and petrochemical" and "non-metallic minerals". All effects combined led to a total decrease of 3.4 Mtoe in final energy consumption of industry. In contrast to Germany, Poland realised large improvements in energy efficiency in the period considered. Reasons for this difference lie in the fact that Germany already restructured its industry in the 1990s and that the energy efficiency level of Poland was much lower than in Germany before 2000; hence, larger improvements were possible.

As shown in Fig. 17, the changes in final energy consumption in the sector households in Germany were mainly driven by rising energy efficiency (-21 Mtoe) due to improvements regarding the specific energy consumption for space heating ( $-38 \%$ from 2000 to 2015). Effects, such as increasing size of dwellings, decreasing household size as well as increasing equipment with electric appliances and lighting, counteracted this decrease. These comfort, behavioural and social developments led to an increase of 7.3 Mtoe, while changes in weather had an effect of + 1.8 Mtoe. Germany's slightly deceasing population

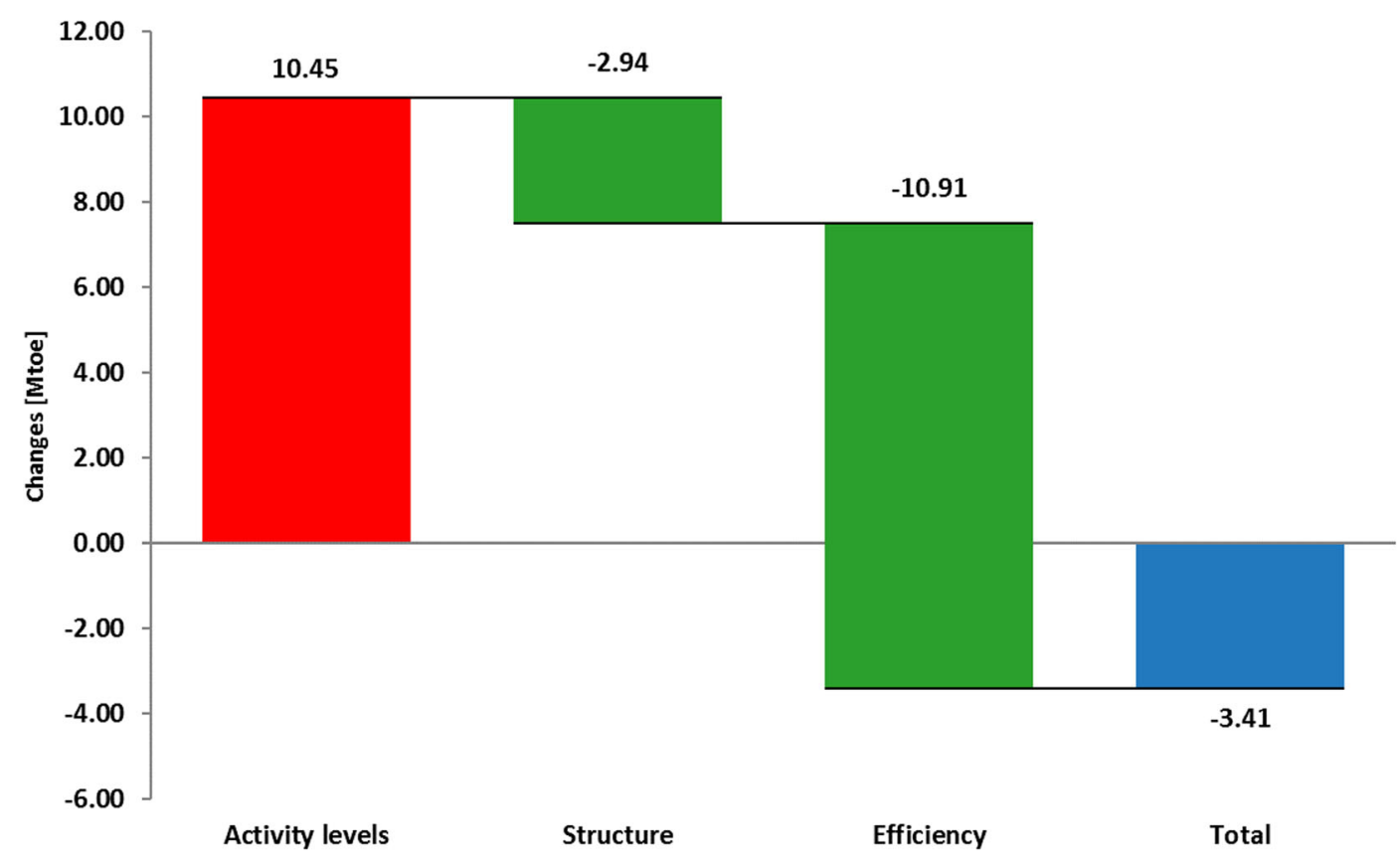

Fig. 16 Changes in final energy consumption of industry (Poland, 2000 to 2015) 


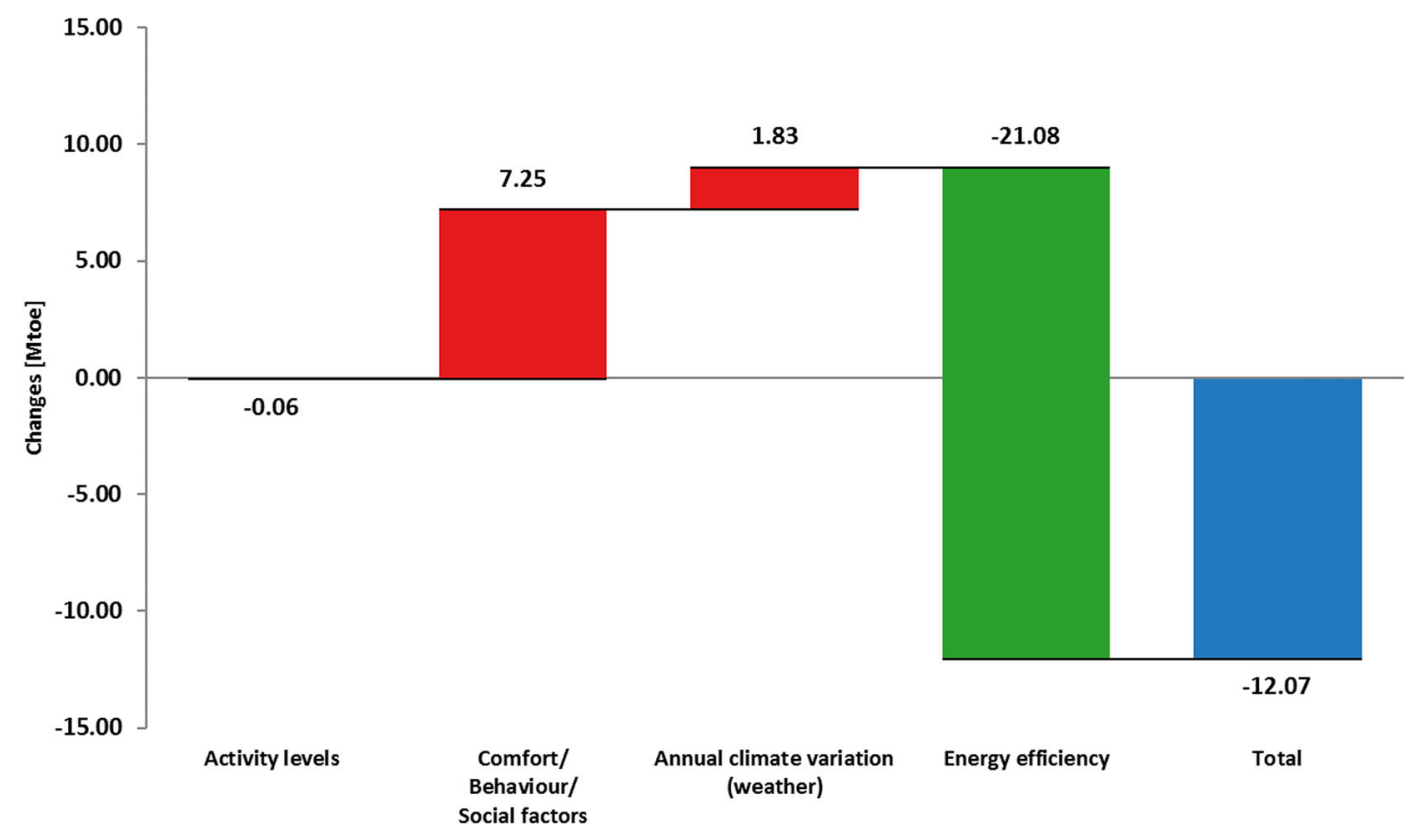

Fig. 17 Changes in final energy consumption of households (Germany, 2000 to 2015)

$(-0.1 \%$ in the period 2000 to 2015$)$ reduced the final energy consumption of households by only 0.06 Mtoe, which in total resulted in a change in final energy consumption of 12 Mtoe from 2000 to 2015.

Households' final energy consumption in Poland shows a similar structure in changes as in
Germany (see Fig. 18). However, energy efficiency improvements are smaller than in Germany as the specific energy consumption for space heating decreased by only $23 \%$ in the time period considered. This results in a decrease by 2.6 Mtoe attributed to energy efficiency, while this was counteracted by weather effects and rising comfort

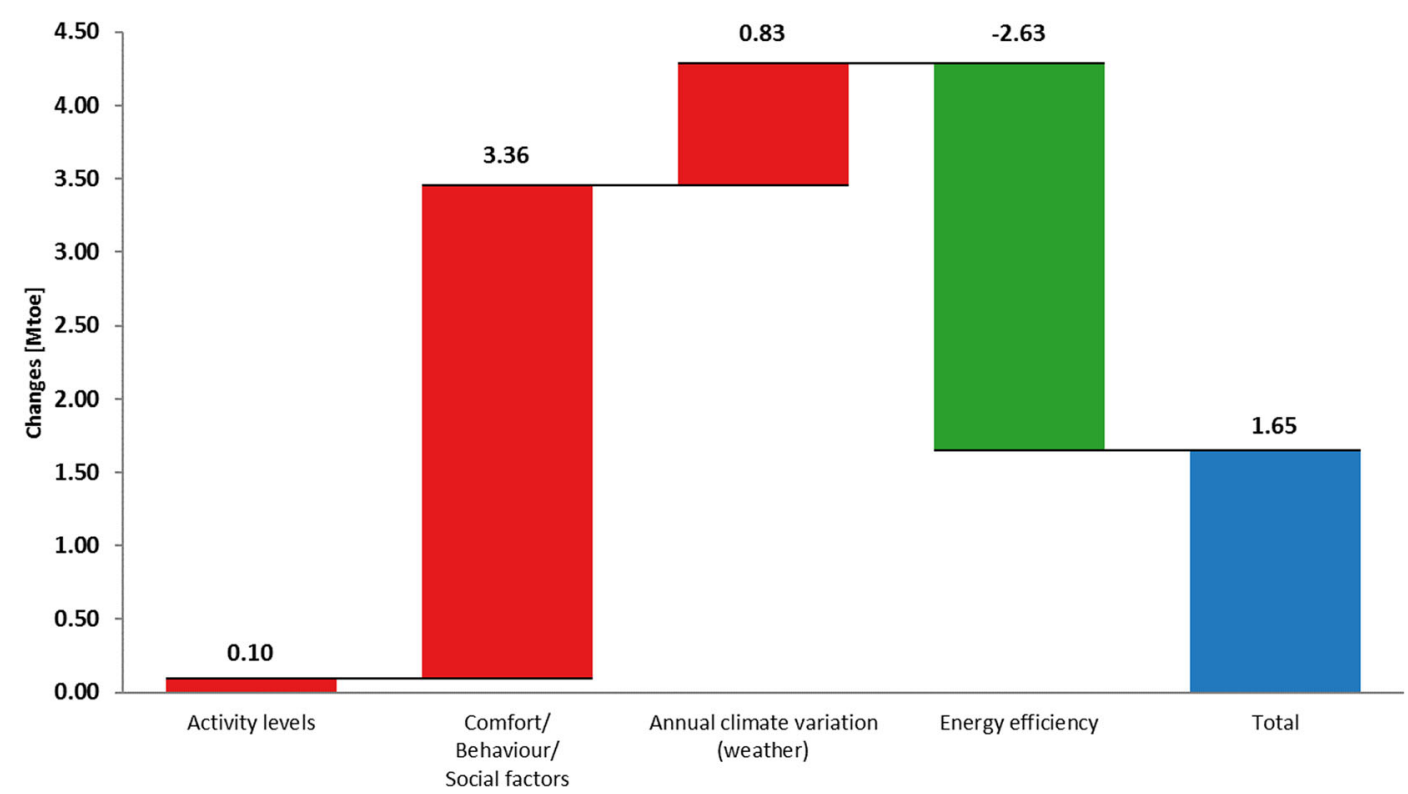

Fig. 18 Changes in final energy consumption of households (Poland, 2000 to 2015) 
in Poland's households. The consumption for electric appliances and lighting rose by $50 \%$ from 2000 to 2015. This increase in comfort led to an increase by 3.4 Mtoe. The slightly increasing population of Poland had a small increasing effect with 0.1 Mtoe. All these effects combined result in an increase in final energy consumption in Poland's households of 1.65 Mtoe.

The changes in energy consumption in Germany's transportation sector were mostly driven upwards by a rise of activity regarding road transport in both passenger and freight transport, with + $14 \%$ and $+19 \%$, respectively. Overall activity of the sector rose by $13 \%$ for passenger and $15 \%$ for goods transport. The shift between the modes of transport only account for a change of 0.21 Mtoe, while the improvement of energy efficiency in transport resulted in a decrease of around 13 Mtoe (see Fig. 19). The main share of these improvements was realised in passenger transport as here the total energy intensity dropped by $24 \%$, which is mainly due to more efficient road transport followed by rail and domestic air transport. All effects combined resulted in a reduction of final energy consumption by 3.7 Mtoe.

In the period from 2007 to 2015 , the changes in the transport sector show a similar pattern. While the gains in energy efficiency ( -1.77 Mtoe) were smaller, the effect of modal shift was slightly larger (0.32 Mtoe). Rising activity in transport contributed an effect of +2.8 Mtoe resulting in a total change in final energy consumption by 0.7 Mtoe.

The changes in energy consumption in Poland's transportation sector show a similar pattern (see Fig. 20). These were driven upwards by 7.3 Mtoe through a rise of activity regarding road transport in both passenger and freight transport, with $+29 \%$ and $+162 \%$, respectively. Modal shift had a larger impact with over 2 Mtoe, indicating a strong shift towards road transport. Unlike in Germany's transport sector, energy efficiency in Poland had a smaller effect and resulted in a decrease in final energy consumption by 2 Mtoe. This is a minor effect mainly due to a decreasing efficiency regarding person-kilometres in passenger transport in general $(+12 \%)$ and road transport in particular $(+6 \%)$, which counteracts efficiency gains in freight transport $(-10 \%)$. As energy efficiency could not counteract the increase in activity, the total change led to an increase in total final energy consumption with 7.3 Mtoe. The reason for the degradation of the efficiency in passenger transport is the shift towards larger cars.

For the period from 2007 to 2015, a similar development can be observed. However, while the impact of rising activity of the sector is only slightly lower (5 Mtoe), the effect of energy improvement in transport is relatively high $(-4.3$ Mtoe) compared to the total period. Together with a slightly smaller effect of modal shift $(+1.2$ Mtoe), the total effect adds up to about 2 Mtoe.

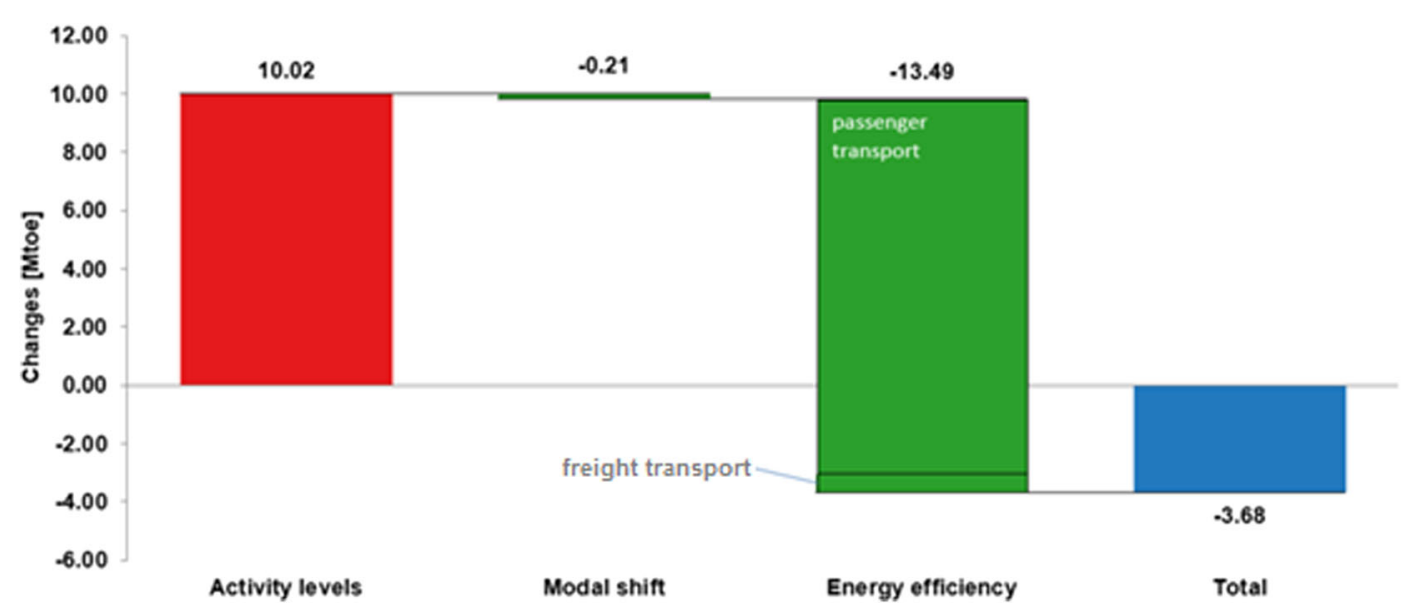

Fig. 19 Changes in final energy consumption of transport (Germany, 2000 to 2015) 


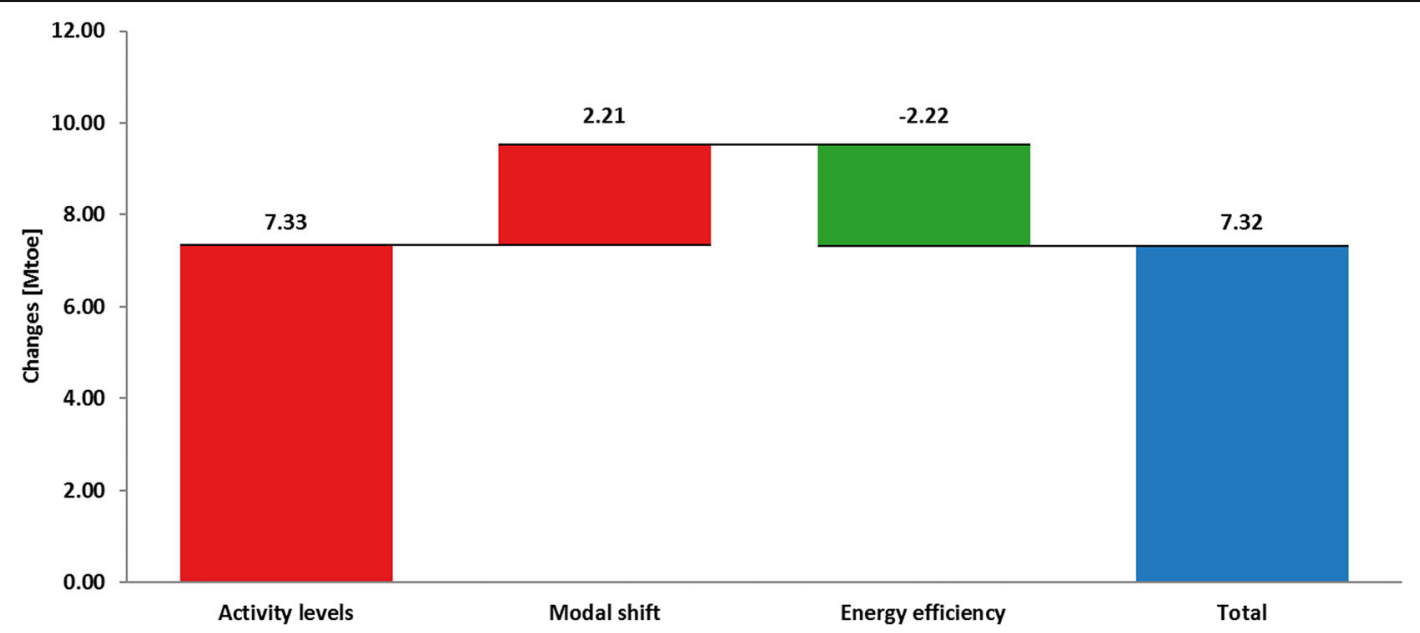

Fig. 20 Changes in final energy consumption of transport (Poland, 2000 to 2015)

The service sector in Germany increased its final energy consumption in the period from 2000 to 2015 by almost 5 Mtoe (see Fig. 21). This was mainly due to the increase of activity by $17 \%$, which led to an increase of about 5 Mtoe. At the same time, energy intensity in the sector dropped slightly by about $1 \%$ resulting in a decrease of 0.2 Mtoe.

In the time from 2007 to 2015 , the energy consumption of Germany's services sector rose by 3.9 Mtoe. This was mainly due to an increase of activity by $10 \%$ resulting in an effect of +3 Mtoe, while a decrease in energy efficiency of $3 \%$ added 0.9 Mtoe.
Changes in Germany's agricultural sector were only partly driven by decreasing activity and more by (apparently) decreasing efficiency in the sector. The decrease of activity in form of gross value added by $14 \%$ contributed about 0.6 Mtoe to the total change of 2.8 Mtoe. An energy efficiency decrease of $10 \%$ resulted in an increase of 1 Mtoe (see Fig. 21).

In Poland's service sector, the increase in final energy consumption due to additional activity of $+19 \%$ was smaller and resulted in an increase by 1.1 Mtoe (see Fig. 22). At the same time, the energy intensity of the sector increased rapidly by $31 \%$, which resulted in almost

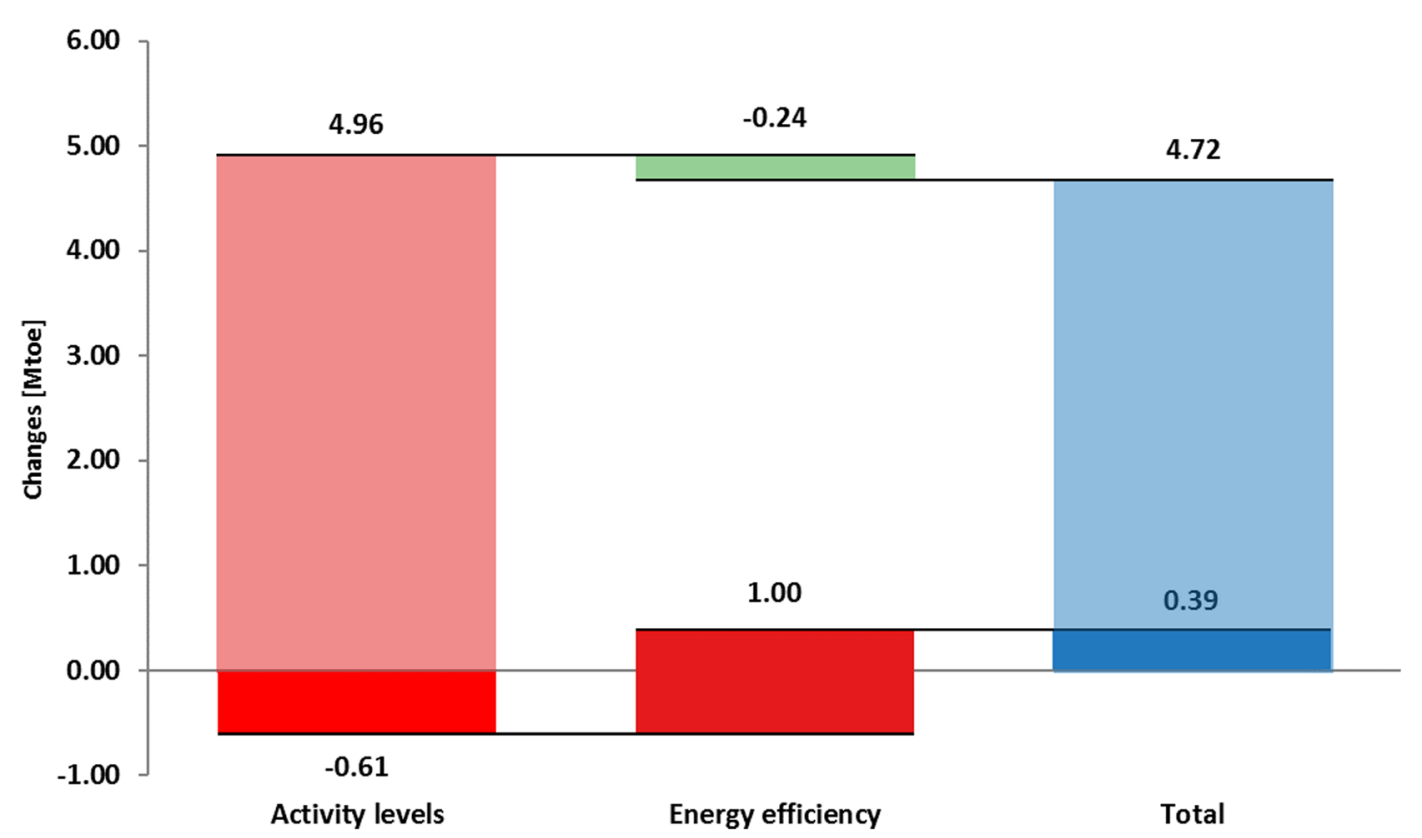

Fig. 21 Changes in final energy consumption of services (semi-transparent) and agriculture (Germany, 2000 to 2015) 


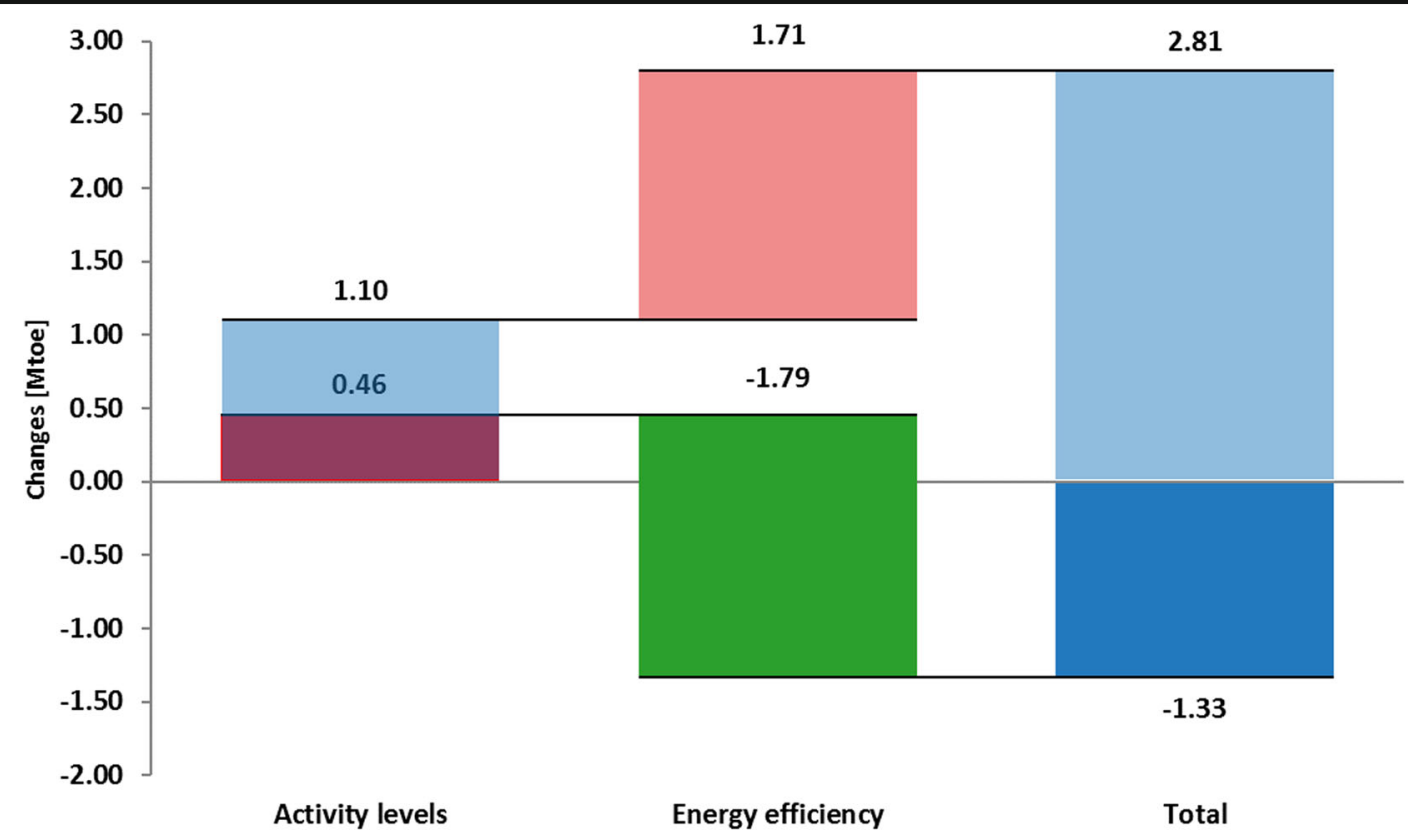

Fig. 22 Changes in final energy consumption of services (semi-transparent) and agriculture (Poland, 2000 to 2015)

2 Mtoe. All these effects add up to a total increase of the final energy consumption of 2.8 Mtoe or $56 \%$. The reason for the increasing energy intensity is not a loss in efficiency but rather due to larger equipment of service sector buildings with energy consuming devices.

In the period from 2007 to 2015 , energy consumption in the sector increased by $10 \%$. The activity grew by $12 \%$, while energy intensity dropped by $1.7 \%$. These developments resulted in effects of +0.8 and 0.12 Mtoe, respectively. The total change in services was +0.8 Mtoe. The fact that energy intensity was decreased after 2007 compared to the period since 2000 may be due to the impacts of thermal building standards.

Final energy consumption of Poland's agriculture was driven by increasing activity of over $12 \%$ and strong improvements of energy efficiency by $37 \%$ in the sector. Growing gross value added contributed 0.5 Mtoe, while energy efficiency gains resulted in a reduction of about 1.8 Mtoe. Overall, the final energy consumption of Poland's agriculture decreased by almost 1.3 Mtoe.

\section{Discussion}

Overall, the final energy consumption in the European Union decreased by about 50 Mtoe in the period from 2000 to 2015. Most of this decrease is due to efficiency gains in all sectors, which more than counteracted all increasing effects (see Fig. 23). The largest share of these efficiency gains was realised in industry ( -85 Mtoe) followed by the households sector ( -69 Mtoe). In households, the main energy efficiency gains resulted from more efficient space heating (technologies) with a decrease by -60 Mtoe. In industry, most changes occurred in the sub-sectors "primary metals" and "chemicals and petrochemicals". To conclude, the changes in the industry sector were found to contribute substantially to the reduction of final energy consumption in the EU28, resulting in a decrease of its total final energy by almost $18 \%$ between 2000 and 2015.

This development can be assumed to be linked to the Energy Efficiency Directive, which includes several measures aiming at energy efficiency in industry, such as the implementation of energy audits and energy management systems (Article 8 EED).

The EU15 $5^{4}$ countries show a reduction of energy consumption due to increasing energy

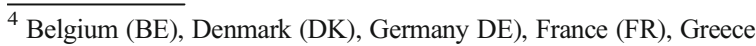
(EL), Ireland (IE), Italy (IT), Luxembourg (LU), The Netherlands (NL), Portugal (PT), Spain (ES) and United Kingdom (UK)
} 
Fig. 23 Overview of factors for the EU28 (sorted by size from positive to negative)

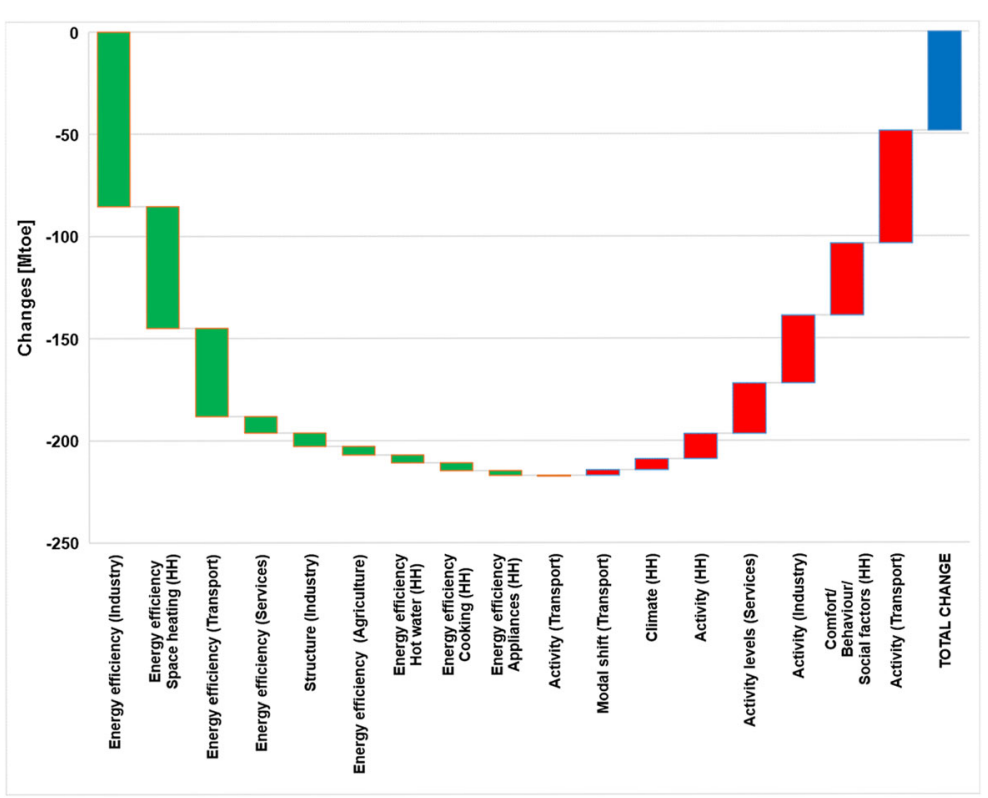

efficiency in industry. The exception in the general development in this group is Austria, for which energy use increased due to decreasing energy efficiency especially in the sub-sector "primary metals".

New member states show a similar trend, while the gains through energy efficiency are compensated for by increasing activity in the period from 2000 to 2015, which draws a similar picture to Fernández González et al. (2013) for the period from 1995 to 2010.

The energy use of households in EU15 countries showed relatively small decreases or even slight increases (e.g. Italy). Energy efficiency improvements in households are reduced by increasing comfort (i.e. larger dwellings) and population growth, which Holzmann et al. (2013) also observed for final energy consumption in Austria. Italy shows a reduction in energy efficiency in households, which combined with increasing population and comfort levels led to a strong increase of final energy consumption in households. However, overall in the European Union energy efficiency plays an important role in the development of energy consumption in households.
This can be assumed to be linked to the strong energy efficiency policies in the sector; the effects of which are weakened mostly by the increase of comfort levels and equipment rates as our analysis shows. Namely, these are the Energy Performance of Buildings Directive (2010/31/EU) and the Ecodesign Directive (2009/125/EC).

Unlike the other EU member states, Sweden shows a decreasing effect of comfort/behaviour/social factors due to an increasing number of persons per household, which counteracts the increase due to the rise in comfort (larger dwellings).

The largest absolute impact on the reduction of final energy consumption in the period from 2000 to 2015 is contributed by the UK with -21.4 Mtoe ($14.3 \%)$, followed by France (-11.1 Mtoe, $-7.2 \%$ ) and Italy $(-8.4$ Mtoe, $-6.6 \%)$. These countries also have realised the highest improvements in energy efficiency in industry, which contributed most energy savings. These improvements were mainly realised in the sub-sectors "primary metals" and "chemicals and petrochemicals", which are also identified by Bertoldi et al. (2018) as the subsectors with the most energy efficiency progress in industry. 
Poland shows the highest increase in final energy consumption with +7 Mtoe $(+12.8 \%)$ followed by Austria (+ 4 Mtoe, $+15.5 \%)$ and Lithuania (+ 1 Mtoe), which also shows the highest relative increase in final energy consumption in the EU (together with Malta; both $+29 \%$ ). In these countries, increased energy consumption in transport has been responsible for the increasing energy consumption due to a rising activity in the sector.

Transport had a significant increasing impact on the energy consumption in the European Union as a whole. The main reason for this development is the strong growth in the activity of both passenger and freight transport, in particular regarding road transport and aviation. While efficiency gains weaken this development, they cannot compensate for the growth in activity in this sector. Most of these efficiency gains were realised in only a few countries, namely Germany, Spain, France and the UK.

It can be assumed that the results we produced are accurate within the limits of the method, because the data used is highly consistent. If this consistency were lower, the results could have been distorted due to the properties of the LMDI method regarding inconsistencies in underlying data.

Furthermore, very few missing data points in a large data set were replaced, so that this imputation has only a small influence on the overall quality of the results.

\section{Conclusions}

We decomposed the changes in final energy consumption of five demand sectors using the logarithmic mean Divisia index method for the EU28 and its member states.

The developments observed imply several possible policy recommendations to steer the future development of final energy consumption in the European Union towards the fulfilment of the targets set for 2020 and 2030.

Compared to the other sectors, the transport sector is particularly predestined to be targeted by future energy efficiency policies as here only small energy savings were realised, especially in the new member states of the European Union. Our analysis shows cumulated energy efficiency gains of 32 Mtoe, while the increase in activity in the member states adds up to 40 Mtoe.

Thus, energy efficiency in transport should be targeted by an increased policy intensity to counteract rising activity and leading to the further reduction of final energy consumption in this sector. This is especially the case for new member states, e.g. Poland, showing an increase of $74 \%$ in the period from 2000 to 2015. At the same time, the sector transport has so far received only little attention from energy efficiency policies in the European and national context.

In other sectors, a large degree of the activity changes are compensated for by increases in energy efficiency and changes in the sector structure in industry.

As shown in our previous analysis of the changes in primary energy consumption using IDA, the decrease in final energy consumption is a major factor for reducing primary energy consumption of the European Union besides the penetration of renewable energies (Reuter et al. 2017). The analysis of final energy savings presented in this paper offers insights, which can help to design strategies for target achievement in a European and international context.

Our analysis leads to interesting topics for future research. For example, an in-depth analysis of individual sectors and countries, which could not be included here due to the limitations of the method and data, would be an interesting option. For this purpose, the households and transport sectors would be of particular interest.

For the former, an investigation of the effects in households affected by energy poverty would be appropriate. To achieve the ambitious goals in the building sector, this group and its specific needs must not be ignored. Thus, future policies regarding energy efficiency in buildings should also include specific elements aiming at the special barriers that particularly affect this group.

\section{Compliance with ethical standards}

Conflict of interest The authors declare that they have no conflict of interest. 
Appendix

Table 4 Overview of results for all member states (except LU, MT) (2000 to 2015) Note: The colours indicate the highest negative value in green to the highest positive value in red by row. Values in million tonnes of oil equivalent

\begin{tabular}{|c|c|c|c|c|c|c|c|c|}
\hline & & $\begin{array}{l}\text { Total } \\
\text { change }\end{array}$ & $\begin{array}{l}\text { Activity } \\
\text { levels }\end{array}$ & Structure & $\begin{array}{l}\text { Modal } \\
\text { shift }\end{array}$ & $\begin{array}{l}\text { Comfort/ } \\
\text { Behaviour/ } \\
\text { Social } \\
\text { factors }\end{array}$ & $\begin{array}{l}\text { Annual } \\
\text { climate } \\
\text { variation } \\
\text { (weather) } \\
\end{array}$ & $\begin{array}{l}\text { Energy } \\
\text { efficiency }\end{array}$ \\
\hline \multirow{5}{*}{ AT } & Industry & 1.82 & 2.28 & -2.37 & 0.00 & 0.00 & 0.00 & 1.92 \\
\hline & Households & -0.36 & 0.46 & 0.00 & 0.00 & 0.84 & 0.08 & -1.75 \\
\hline & Transport & 2.01 & 1.22 & 0.00 & -0.35 & 0.00 & 0.00 & 1.13 \\
\hline & Services & 0.18 & 0.55 & 0.00 & 0.00 & 0.00 & 0.00 & -0.37 \\
\hline & Agriculture & 0.02 & 0.05 & 0.00 & 0.00 & 0.00 & 0.00 & -0.02 \\
\hline \multirow{5}{*}{ BE } & Industry & -2.21 & 1.89 & 0.40 & 0.00 & 0.00 & 0.00 & -4.50 \\
\hline & Households & -1.34 & 0.82 & 0.00 & 0.00 & 4.06 & 0.27 & -6.49 \\
\hline & Transport & -0.36 & -0.48 & 0.00 & -0.32 & 0.00 & 0.00 & 0.43 \\
\hline & Services & 1.08 & 0.81 & 0.00 & 0.00 & 0.00 & 0.00 & 0.27 \\
\hline & Agriculture & -0.06 & 0.08 & 0.00 & 0.00 & 0.00 & 0.00 & -0.14 \\
\hline \multirow{5}{*}{ BG } & Industry & -1.25 & 1.40 & -0.62 & 0.00 & 0.00 & 0.00 & -2.03 \\
\hline & Households & 0.04 & -0.28 & 0.00 & 0.00 & 0.62 & -0.01 & -0.29 \\
\hline & Transport & 1.39 & 2.27 & 0.00 & 0.20 & 0.00 & 0.00 & -1.08 \\
\hline & Services & 0.35 & 0.27 & 0.00 & 0.00 & 0.00 & 0.00 & 0.09 \\
\hline & Agriculture & -0.13 & -0.09 & 0.00 & 0.00 & 0.00 & 0.00 & -0.04 \\
\hline \multirow{5}{*}{ HR } & Industry & -0.29 & 0.15 & -0.01 & 0.00 & 0.00 & 0.00 & -0.42 \\
\hline & Households & 0.12 & -0.12 & 0.00 & 0.00 & 0.53 & -0.01 & -0.28 \\
\hline & Transport & 0.59 & 0.90 & 0.00 & 0.16 & 0.00 & 0.00 & -0.47 \\
\hline & Services & 0.25 & 0.14 & 0.00 & 0.00 & 0.00 & 0.00 & 0.11 \\
\hline & Agriculture & -0.06 & -0.02 & 0.00 & 0.00 & 0.00 & 0.00 & -0.03 \\
\hline \multirow{5}{*}{ CY } & Industry & -0.24 & -0.15 & 0.05 & 0.00 & 0.00 & 0.00 & -0.15 \\
\hline & Households & 0.14 & 0.05 & 0.00 & 0.00 & 0.05 & -0.04 & 0.09 \\
\hline & Transport & -0.16 & -0.18 & 0.00 & 0.00 & 0.00 & 0.00 & 0.02 \\
\hline & Services & 0.07 & 0.05 & 0.00 & 0.00 & 0.00 & 0.00 & 0.02 \\
\hline & Agriculture & 0.03 & -0.01 & 0.00 & 0.00 & 0.00 & 0.00 & 0.04 \\
\hline \multirow{5}{*}{ CZ } & Industry & -2.66 & 5.45 & -3.65 & 0.00 & 0.00 & 0.00 & -4.46 \\
\hline & Households & 0.27 & 0.17 & 0.00 & 0.00 & 1.01 & 0.18 & -1.09 \\
\hline & Transport & 2.21 & 0.94 & 0.00 & 0.15 & 0.00 & 0.00 & 1.12 \\
\hline & Services & -0.57 & 0.41 & 0.00 & 0.00 & 0.00 & 0.00 & -0.97 \\
\hline & Agriculture & -0.05 & -0.02 & 0.00 & 0.00 & 0.00 & 0.00 & -0.04 \\
\hline \multirow{4}{*}{ DK } & Industry & -0.81 & -0.08 & -0.31 & 0.00 & 0.00 & 0.00 & -0.42 \\
\hline & Households & 0.09 & 0.25 & 0.00 & 0.00 & 0.43 & 0.04 & -0.62 \\
\hline & Transport & 0.14 & 0.08 & 0.00 & 0.02 & 0.00 & 0.00 & 0.04 \\
\hline & Services & 0.02 & 0.20 & 0.00 & 0.00 & 0.00 & 0.00 & -0.18 \\
\hline
\end{tabular}




\begin{tabular}{|c|c|c|c|c|c|c|c|c|}
\hline & & $\begin{array}{l}\text { Total } \\
\text { change }\end{array}$ & $\begin{array}{l}\text { Activity } \\
\text { levels }\end{array}$ & Structure & $\begin{array}{l}\text { Modal } \\
\text { shift }\end{array}$ & $\begin{array}{l}\text { Comfort/ } \\
\text { Behaviour/ } \\
\text { Social } \\
\text { factors }\end{array}$ & $\begin{array}{l}\text { Annual } \\
\text { climate } \\
\text { variation } \\
\text { (weather) }\end{array}$ & $\begin{array}{l}\text { Energy } \\
\text { efficiency }\end{array}$ \\
\hline & Agriculture & -0.11 & 0.00 & 0.00 & 0.00 & 0.00 & 0.00 & -0.11 \\
\hline \multirow{5}{*}{ EE } & Industry & -0.05 & 0.33 & -0.13 & 0.00 & 0.00 & 0.00 & -0.25 \\
\hline & Households & -0.07 & -0.05 & 0.00 & 0.00 & 0.12 & 0.05 & -0.19 \\
\hline & Transport & 0.03 & -0.05 & 0.00 & 0.15 & 0.00 & 0.00 & -0.08 \\
\hline & Services & 0.18 & 0.06 & 0.00 & 0.00 & 0.00 & 0.00 & 0.11 \\
\hline & Agriculture & 0.07 & 0.03 & 0.00 & 0.00 & 0.00 & 0.00 & 0.05 \\
\hline \multirow{5}{*}{ FI } & Industry & -1.51 & 0.44 & -2.03 & 0.00 & 0.00 & 0.00 & 0.08 \\
\hline & Households & 0.41 & 0.27 & 0.00 & 0.00 & 0.60 & 0.11 & -0.57 \\
\hline & Transport & 0.17 & -0.25 & 0.00 & 0.00 & 0.00 & 0.00 & 0.42 \\
\hline & Services & 0.49 & 0.39 & 0.00 & 0.00 & 0.00 & 0.00 & 0.10 \\
\hline & Agriculture & -0.03 & 0.10 & 0.00 & 0.00 & 0.00 & 0.00 & -0.13 \\
\hline \multirow{5}{*}{ FR } & Industry & -8.71 & 1.37 & 1.45 & 0.00 & 0.00 & 0.00 & -11.53 \\
\hline & Households & -3.12 & 3.45 & 0.00 & 0.00 & 2.97 & 1.13 & -10.67 \\
\hline & Transport & -0.36 & 2.33 & 0.00 & 0.67 & 0.00 & 0.00 & -3.35 \\
\hline & Services & 0.82 & 2.86 & 0.00 & 0.00 & 0.00 & 0.00 & -2.04 \\
\hline & Agriculture & 0.28 & 0.02 & 0.00 & 0.00 & 0.00 & 0.00 & 0.26 \\
\hline \multirow{5}{*}{ DE } & Industry & 3.38 & 10.90 & -4.57 & 0.00 & 0.00 & 0.00 & -2.95 \\
\hline & Households & -12.07 & -0.06 & 0.00 & 0.00 & 7.25 & 1.83 & -21.08 \\
\hline & Transport & -3.68 & 10.02 & 0.00 & -0.21 & 0.00 & 0.00 & -13.49 \\
\hline & Services & 4.72 & 4.96 & 0.00 & 0.00 & 0.00 & 0.00 & -0.24 \\
\hline & Agriculture & 0.39 & -0.61 & 0.00 & 0.00 & 0.00 & 0.00 & 1.00 \\
\hline \multirow{5}{*}{ GR } & Industry & -1.32 & -1.75 & 0.47 & 0.00 & 0.00 & 0.00 & -0.04 \\
\hline & Households & -0.10 & 0.01 & 0.00 & 0.00 & 0.64 & -1.73 & 0.98 \\
\hline & Transport & -0.73 & 0.73 & 0.00 & 0.07 & 0.00 & 0.00 & -1.52 \\
\hline & Services & 0.81 & 0.11 & 0.00 & 0.00 & 0.00 & 0.00 & 0.71 \\
\hline & Agriculture & -0.86 & -0.05 & 0.00 & 0.00 & 0.00 & 0.00 & -0.81 \\
\hline \multirow{5}{*}{ HU } & Industry & 0.72 & 2.18 & -2.30 & 0.00 & 0.00 & 0.00 & 0.84 \\
\hline & Households & 0.35 & -0.21 & 0.00 & 0.00 & 0.52 & 0.01 & 0.04 \\
\hline & Transport & 0.66 & 0.86 & 0.00 & 0.24 & 0.00 & 0.00 & -0.45 \\
\hline & Services & -0.86 & 0.40 & 0.00 & 0.00 & 0.00 & 0.00 & -1.26 \\
\hline & Agriculture & -0.10 & -0.02 & 0.00 & 0.00 & 0.00 & 0.00 & -0.07 \\
\hline \multirow{5}{*}{ IE } & Industry & -0.08 & 0.78 & -0.52 & 0.00 & 0.00 & 0.00 & -0.33 \\
\hline & Households & 0.20 & 0.53 & 0.00 & 0.00 & 0.55 & 0.02 & -0.90 \\
\hline & Transport & -0.38 & 0.17 & 0.00 & 0.03 & 0.00 & 0.00 & -0.58 \\
\hline & Services & -0.12 & 0.40 & 0.00 & 0.00 & 0.00 & 0.00 & -0.53 \\
\hline & Agriculture & -0.10 & 0.00 & 0.00 & 0.00 & 0.00 & 0.00 & -0.10 \\
\hline \multirow{4}{*}{ IT } & Industry & -13.71 & -2.97 & 2.23 & 0.00 & 0.00 & 0.00 & -12.98 \\
\hline & Households & 4.90 & 1.88 & 0.00 & 0.00 & 1.36 & 1.07 & 0.58 \\
\hline & Transport & -3.12 & -4.91 & 0.00 & -1.28 & 0.00 & 0.00 & 3.07 \\
\hline & Services & 3.83 & 1.03 & 0.00 & 0.00 & 0.00 & 0.00 & 2.80 \\
\hline
\end{tabular}




\begin{tabular}{|c|c|c|c|c|c|c|c|c|}
\hline & & $\begin{array}{l}\text { Total } \\
\text { change }\end{array}$ & $\begin{array}{l}\text { Activity } \\
\text { levels }\end{array}$ & Structure & $\begin{array}{l}\text { Modal } \\
\text { shift }\end{array}$ & $\begin{array}{l}\text { Comfort/ } \\
\text { Behaviour/ } \\
\text { Social } \\
\text { factors }\end{array}$ & $\begin{array}{l}\text { Annual } \\
\text { climate } \\
\text { variation } \\
\text { (weather) }\end{array}$ & $\begin{array}{l}\text { Energy } \\
\text { efficiency }\end{array}$ \\
\hline & Agriculture & -0.24 & -0.17 & 0.00 & 0.00 & 0.00 & 0.00 & -0.07 \\
\hline \multirow{5}{*}{ LV } & Industry & 0.21 & 0.24 & 0.00 & 0.00 & 0.00 & 0.00 & -0.03 \\
\hline & Households & -0.22 & -0.22 & 0.00 & 0.00 & 0.30 & 0.06 & -0.36 \\
\hline & Transport & 0.40 & 0.34 & 0.00 & 0.24 & 0.00 & 0.00 & -0.19 \\
\hline & Services & 0.12 & 0.05 & 0.00 & 0.00 & 0.00 & 0.00 & 0.06 \\
\hline & Agriculture & 0.05 & 0.04 & 0.00 & 0.00 & 0.00 & 0.00 & 0.01 \\
\hline \multirow{5}{*}{ LT } & Industry & 0.20 & 0.71 & -0.06 & 0.00 & 0.00 & 0.00 & -0.45 \\
\hline & Households & 0.00 & -0.25 & 0.00 & 0.00 & 0.34 & 0.05 & -0.14 \\
\hline & Transport & 0.75 & 0.48 & 0.00 & 0.15 & 0.00 & 0.00 & 0.12 \\
\hline & Services & 0.13 & 0.07 & 0.00 & 0.00 & 0.00 & 0.00 & 0.06 \\
\hline & Agriculture & 0.00 & 0.02 & 0.00 & 0.00 & 0.00 & 0.00 & -0.02 \\
\hline \multirow{5}{*}{ NL } & Industry & -2.24 & -0.10 & 2.84 & 0.00 & 0.00 & 0.00 & -4.98 \\
\hline & Households & -1.27 & 0.63 & 0.00 & 0.00 & 1.57 & 0.19 & -3.66 \\
\hline & Transport & -0.36 & 1.41 & 0.00 & -0.31 & 0.00 & 0.00 & -1.46 \\
\hline & Services & 0.31 & 0.66 & 0.00 & 0.00 & 0.00 & 0.00 & -0.35 \\
\hline & Agriculture & -0.50 & 0.35 & 0.00 & 0.00 & 0.00 & 0.00 & -0.85 \\
\hline \multirow{5}{*}{ PL } & Industry & -3.41 & 10.45 & -2.94 & 0.00 & 0.00 & 0.00 & -10.91 \\
\hline & Households & 1.65 & 0.09 & 0.00 & 0.00 & 3.41 & 0.83 & -2.68 \\
\hline & Transport & 7.32 & 7.33 & 0.00 & 2.21 & 0.00 & 0.00 & -2.22 \\
\hline & Services & 2.81 & 1.10 & 0.00 & 0.00 & 0.00 & 0.00 & 1.71 \\
\hline & Agriculture & -1.33 & 0.46 & 0.00 & 0.00 & 0.00 & 0.00 & -1.79 \\
\hline \multirow{5}{*}{ PT } & Industry & -1.87 & -1.22 & 0.56 & 0.00 & 0.00 & 0.00 & -1.21 \\
\hline & Households & -0.27 & 0.02 & 0.00 & 0.00 & 4.69 & -0.07 & -4.91 \\
\hline & Transport & -0.02 & 1.42 & 0.00 & 0.02 & 0.00 & 0.00 & -1.46 \\
\hline & Services & 0.56 & 0.42 & 0.00 & 0.00 & 0.00 & 0.00 & 0.14 \\
\hline & Agriculture & -0.38 & -0.01 & 0.00 & 0.00 & 0.00 & 0.00 & -0.37 \\
\hline \multirow{5}{*}{ RO } & Industry & -2.82 & 4.35 & -2.15 & 0.00 & 0.00 & 0.00 & -5.02 \\
\hline & Households & -1.03 & -0.95 & 0.00 & 0.00 & 2.64 & -0.11 & -2.62 \\
\hline & Transport & 1.03 & 1.29 & 0.00 & 0.27 & 0.00 & 0.00 & -0.53 \\
\hline & Services & 0.80 & 0.19 & 0.00 & 0.00 & 0.00 & 0.00 & 0.61 \\
\hline & Agriculture & 0.06 & -0.26 & 0.00 & 0.00 & 0.00 & 0.00 & 0.32 \\
\hline \multirow{5}{*}{ SI } & Industry & -0.20 & 0.33 & -0.03 & 0.00 & 0.00 & 0.00 & -0.50 \\
\hline & Households & -0.02 & 0.04 & 0.00 & 0.00 & 0.13 & 0.02 & -0.20 \\
\hline & Transport & 0.30 & 0.29 & 0.00 & 0.05 & 0.00 & 0.00 & -0.04 \\
\hline & Services & -0.09 & 0.09 & 0.00 & 0.00 & 0.00 & 0.00 & -0.18 \\
\hline & Agriculture & 0.00 & 0.00 & 0.00 & 0.00 & 0.00 & 0.00 & 0.00 \\
\hline \multirow{4}{*}{ SK } & Industry & -0.11 & 5.54 & -0.93 & 0.00 & 0.00 & 0.00 & -4.72 \\
\hline & Households & -0.60 & 0.01 & 0.00 & 0.00 & 0.14 & -0.06 & -0.68 \\
\hline & Transport & 0.70 & 0.30 & 0.00 & 0.24 & 0.00 & 0.00 & 0.16 \\
\hline & Services & -0.90 & 0.43 & 0.00 & 0.00 & 0.00 & 0.00 & -1.33 \\
\hline
\end{tabular}




\begin{tabular}{|c|c|c|c|c|c|c|c|c|}
\hline & & $\begin{array}{l}\text { Total } \\
\text { change }\end{array}$ & $\begin{array}{l}\text { Activity } \\
\text { levels }\end{array}$ & Structure & $\begin{array}{l}\text { Modal } \\
\text { shift }\end{array}$ & $\begin{array}{l}\text { Comfort/ } \\
\text { Behaviour/ } \\
\text { Social } \\
\text { factors }\end{array}$ & $\begin{array}{l}\text { Annual } \\
\text { climate } \\
\text { variation } \\
\text { (weather) }\end{array}$ & $\begin{array}{l}\text { Energy } \\
\text { efficiency }\end{array}$ \\
\hline & Agriculture & -0.06 & 0.11 & 0.00 & 0.00 & 0.00 & 0.00 & -0.17 \\
\hline \multirow{5}{*}{ ES } & Industry & -6.47 & -2.69 & 0.56 & 0.00 & 0.00 & 0.00 & -4.33 \\
\hline & Households & 2.88 & 1.87 & 0.00 & 0.00 & 2.36 & -0.24 & -1.12 \\
\hline & Transport & 0.24 & 8.00 & 0.00 & -0.47 & 0.00 & 0.00 & -7.30 \\
\hline & Services & 3.87 & 2.88 & 0.00 & 0.00 & 0.00 & 0.00 & 0.99 \\
\hline & Agriculture & -0.31 & -0.24 & 0.00 & 0.00 & 0.00 & 0.00 & -0.07 \\
\hline \multirow{5}{*}{ SE } & Industry & -2.74 & 5.07 & -6.18 & 0.00 & 0.00 & 0.00 & -1.62 \\
\hline & Households & -0.10 & 0.75 & 0.00 & 0.00 & -0.30 & 0.43 & -0.98 \\
\hline & Transport & 0.48 & 1.46 & 0.00 & -0.05 & 0.00 & 0.00 & -0.93 \\
\hline & Services & -0.45 & 1.52 & 0.00 & 0.00 & 0.00 & 0.00 & -1.97 \\
\hline & Agriculture & -0.36 & 0.12 & 0.00 & 0.00 & 0.00 & 0.00 & -0.49 \\
\hline \multirow{5}{*}{ UK } & Industry & -12.20 & -1.10 & -1.97 & 0.00 & 0.00 & 0.00 & -9.13 \\
\hline & Households & -6.55 & 3.97 & 0.00 & 0.00 & 3.70 & -0.16 & -14.06 \\
\hline & Transport & -0.62 & 3.86 & 0.00 & -1.06 & 0.00 & 0.00 & -3.42 \\
\hline & Services & -1.86 & 3.39 & 0.00 & 0.00 & 0.00 & 0.00 & -5.25 \\
\hline & Agriculture & -0.13 & 0.00 & 0.00 & 0.00 & 0.00 & 0.00 & -0.13 \\
\hline
\end{tabular}

Open Access This article is distributed under the terms of the Creative Commons Attribution 4.0 International License (http:// creativecommons.org/licenses/by/4.0/), which permits unrestricted use, distribution, and reproduction in any medium, provided you give appropriate credit to the original author(s) and the source, provide a link to the Creative Commons license, and indicate if changes were made.

Publisher's Note Springer Nature remains neutral with regard to jurisdictional claims in published maps and institutional affiliations.

\section{References}

Achour, H., \& Belloumi, M. (2016). Decomposing the influencing factors of energy consumption in Tunisian transportation sector using the LMDI method. Transport Policy, 52, 64 71. https://doi.org/10.1016/j.tranpol.2016.07.008.

Ang, B. W. (2004). Decomposition analysis for policymaking in energy: which is the preferred method? Energy Policy, 32(9), 1131-1139. https://doi.org/10.1016/s0301-4215(03)00076-4.

Ang, B.W. (2005). The LMDI approach to decomposition analysis: a practical guide. Energy Policy, 33(7):867871. https://doi.org/10.1016/j.enpol.2003.10.010.

Ang, B. W. (2015). LMDI decomposition approach: a guide for implementation. Energy Policy, 86, 233-238. https://doi. org/10.1016/j.enpol.2015.07.007.
Ang, B. W., \& Choi, K. (1997). Decomposition of aggregate energy and gas emission intensities for industry: a refined Divisia index method. The Energy Journal, 18(3), 59-73 Available online at http://www.jstor.org/stable/41322738.

Ang, B. W., \& Zhang, F. Q. (2000). A survey of index decomposition analysis in energy and environmental studies. Energy, 25(12), 1149-1176. https://doi.org/10.1016/S0360-5442(00)00039-6.

Ang, B. W., Huang, H. C., \& Mu, A. R. (2009). Properties and linkages of some index decomposition analysis methods. Energy Policy, 37(11), 4624-4632. https://doi.org/10.1016 /j.enpol.2009.06.017.

Bertoldi, P., Diluiso F., Castellazzi L., Labanca N. \& Ribeiro Serrenho T. (2018). Energy consumption and energy efficiency trends in the EU-28 2000-2015, EUR 29104 EN. Luxembourg: Publications Office of the European Union. https://doi.org/10.2760/6684.

Bertoldi, P., López-Lorente, J., Labanca, N. (2016). Energy consumption and energy efficiency trends in the EU-28 20002014. EUR 27972 EN. https://doi.org/10.2788/581574.

Capros, P., Mantzos, L., Papandreou, V., \& Tasios, N. (2008). European energy and transport trends to 2030. Update 2007. Luxembourg: EUR-OP.

Capros, P., de Vita, A., Tasios, N., Papadopoulos, P., Siskos, E., Apostolaki, M., et al. (2013). EU energy, transport and GHG emissions: trends to 2030: reference scenario 2013. Luxembourg: Office for Official Publications of the European Communities.

Capros, P., de Vita, A., Tasios, N., Evangelopoulou, S., Forsell, N., Fragiadakis, K., et al. (2016). EU reference scenario 2016. 
Energy, transport and GHG emissions: trends to 2050. Luxembourg: Publications Office.

Chong, C. H., Liu, P., Ma, L., Li, Z., Ni, W., Li, X., \& Song, S. (2017). LMDI decomposition of energy consumption in Guangdong Province, China, based on an energy allocation diagram. Energy, 133, 525-544. https://doi.org/10.1016/j. energy.2017.05.045.

Colinet Carmona, M. J., \& Román Collado, R. (2016). LMDI decomposition analysis of energy consumption in Andalusia (Spain) during 2003-2012. The energy efficiency policy implications. Energy Efficiency, 9(3), 807-823. https://doi. org/10.1007/s12053-015-9402-y.

European Commission. (2012). Directive 2012/27/EU of the European Parliament and of the Council of 25 October 2012 on energy efficiency, amending Directives 2009/125/ EC and 2010/30/EU and repealing directives 2004/8/EC and 2006/32/EC (Official Journal of the European Union L315/1 from 11 November 2012). Available online at http://eur-lex. europa.eu/legal-content/EN/TXT/PDF/?uri=CELEX:32012 L0027. Accessed 15 Sept 2016.

European Commission. (2014). Communication from the commission to the European Parliament and The Council. Energy Efficiency and its contribution to energy security and the 2030 Framework for climate and energy policy. Brussels. Available online at http://ec.europa . eu/energy/sites/ener/files/documents/2014_eec_ communication_adopted_0.pdf. Accessed 15 Sept 2016.

European Commission. (2016a). Communication from the Commission to the European Parliament, the Council, the European Economic and Social Committee, the Committee of the Regions and the European Investment Bank. Clean Energy For All Europeans. Available online at http:/eur-lex. europa.eu/resource.html?uri=cellar:fa6ea15b-b7b0-11e6-9e3 c-01aa75ed71a1.0001.02/DOC_1\&format=PDF. Accessed 15 Sept 2016.

European Commission. (2016b). Statistical pocketbook 2016. EU transport in figures. Edited by Publications Office of the European Union. Luxembourg. Available online at h t t p s : / / e c. e u r o p a .

eu/transport/sites/transport/files/pocketbook2016.pdf . Accessed 15 Sept 2016.

European Council (2014). European Council 23/24 October 2014 conclusions. European Council. Brussels. Available online at https://www.consilium.europa.eu/uedocs/cms data/docs/pressdata/en/ec/145397.pdf. Accessed 15 Sept 2016.

European Parliament; Council of the European Union. (1999). Directive 1999/94/EC of the European Parliament and of the Council of 13 December 1999 relating to the availability of consumer information on fuel economy and $\mathrm{CO} 2$ emissions in respect of the marketing of new passenger cars. Available online at http://eur-lex.europa.eu/legalcontent/EN/TXT/?uri=celex:31999L0094 . Accessed 23 July 2016.

European Parliament; Council of the European Union. (2009a). Decision No 406/2009/EC of the European Parliament and of The Council of 23 April 2009 on the effort of member states to reduce their greenhouse gas emissions to meet the Community's greenhouse gas emission reduction commitments up to 20202009 . Available online at http://eur-lex.
europa.eu/legal-content/EN/TXT/?uri=uriserv:OJ. L_.2009.140.01.0136.01.ENG . Accessed 23 July 2016.

European Parliament; Council of the European Union. (2009b). Directive 2009/125/EC of the European Parliament and of the Council of 21 October 2009 establishing a framework for the setting of ecodesign requirements for energy-related products 2009. Available online at http://eur-lex.europa. eu/legal-content/EN/TXT/?uri=CELEX:32009L0125 . Accessed 23 July 2016.

European Parliament; Council of the European Union. (2009c). Directive 2009/29/EC of the European Parliament and of The Council of 23 April 2009 amending Directive 2003/87/EC so as to improve and extend the greenhouse gas emission allowance trading scheme of the Community. Available online at http://eur-lex.europa.eu/legal-content/EN/ALL/?uri= CELEX:32010L0030 . Accessed 23 July 2016.

European Parliament; Council of the European Union. (2009d). Regulation (EC) No 443/2009 of the European Parliament and of The Council of 23 April 2009 setting emission performance standards for new passenger cars as part of the Community's integrated approach to reduce $\mathrm{CO} 2$ emissions from light-duty vehicles. Available online at http://eur-lex. europa.eu/legal-content/EN/TXT/?uri=CELEX:02009 R0443-20140408 . Accessed 15 Sept 2016.

European Parliament, Council of the European Union. (2010). Directive 2010/30/EU of the European Parliament and of the Council of 19 May 2010 on the indication by labelling and standard product information of the consumption of energy and other resources by energy-related products. Available online at http://eur-lex.europa.eu/legalcontent/EN/ALL/?uri=CELEX:32010L0030 . Accessed 15 Sept 2016.

European Parliament; Council of the European Union. (2017). Regulation (EU) 2017/1369 of the European Parliament and of the Council of 4 July 2017 setting a framework for energy labelling and repealing Directive 2010/30/EU. Available online at http://eur-lex.europa.eu/eli/reg/2017 /1369/oj . Accessed 17 Sept 2017.

Fernández González, P., Landajo, M., \& Presno, M. J. (2013). The Divisia real energy intensity indices. Evolution and attribution of percent changes in 20 European countries from 1995 to 2010. Energy, 58, 340-349. https://doi.org/10.1016/j. energy.2013.06.013.

Fernández González, P., Landajo, M., \& Presno, M. J. (2014). Multilevel LMDI decomposition of changes in aggregate energy consumption. A cross country analysis in the EU27. Energy Policy, 68, 576-584. https://doi.org/10.1016/j. enpol.2013.12.065.

Goh, T., \& Ang, B. W. (2018). Tracking economy-wide energy efficiency using LMDI. Approach and practices. Energy Efficiency, 44(9), 682. https://doi.org/10.1007/s12053-0189683-z.

Goh, T., Ang, B. W., Su, B., \& Wang, H. (2018). Drivers of stagnating global carbon intensity of electricity and the way forward. Energy Policy, 113, 149-156. https://doi. org/10.1016/j.enpol.2017.10.058.

Holzmann, A., Adensam, H., Kratena, K., \& Schmid, E. (2013). Decomposing final energy use for heating in the residential sector in Austria. Energy Policy, 62, 607-616. https://doi. org/10.1016/j.enpol.2013.07.027. 
IEA. (2004). Energy Statistics Manual. Paris: OECD Publishing. https://doi.org/10.1787/9789264033986-en.

Karmellos, M., Kopidou, D., \& Diakoulaki, D. (2016). A decomposition analysis of the driving factors of $\mathrm{CO} 2$ (carbon dioxide) emissions from the power sector in the European Union countries. Energy, 94, 680-692. https://doi.org/10.1016/j. energy.2015.10.145.

Kerimray, A., Kolyagin, I., \& Suleimenov, B. (2018). Analysis of the energy intensity of Kazakhstan. From data compilation to decomposition analysis. Energy Efficiency, 11(2), 315-335. https://doi.org/10.1007/s12053-017-9565-9.

Kim, S. (2017). Decomposition analysis of energy consumption in the Korean manufacturing sector. Sustainability, 9(2). https://doi.org/10.3390/su9020202.

Kopidou, D., \& Diakoulaki, D. (2017). Decomposing industrial CO 2 emissions of Southern European countries into production- and consumption-based driving factors. Journal of Cleaner Production, 167, 1325-1334. https://doi. org/10.1016/j.jclepro.2017.05.183.

Li, Y., Chiu, Y. H., Lu, L. C., \& Chiu, C. R. (2018). Evaluation of energy efficiency and air pollutant emissions in Chinese provinces. Energy Efficiency, 223(3), 752. https://doi. org/10.1007/s12053-018-9733-6.

Marrero, G., \& Ramos-Real, F. (2013). Activity sectors and energy intensity. Decomposition analysis and policy implications for European countries (1991-2005). Energies, 6(5), 25212540. https://doi.org/10.3390/en6052521.

Ministère de la Transition écologique et solidaire. (2018). Code de l'énergie. Montants et modalités de versement des aides. MTES. Available online at https://www.legifrance.gouv. fr/affichCode.do;?idSectionTA=LEGISCTA000031748217 \&cidTexte=LEGITEXT000023983208 . Accessed 17 April 2018.

Moutinho, V., Madaleno, M., \& Silva, P. M. (2016). Which factors drive $\mathrm{CO} 2$ emissions in EU-15? Decomposition and innovative accounting. Energy Efficiency, 9(5), 1087-1113. https://doi.org/10.1007/s12053-015-9411-x.

Nie, H., Kemp, R., Vivanco, D. F., \& Vasseur, V. (2016). Structural decomposition analysis of energy-related $\mathrm{CO} 2$ emissions in China from 1997 to 2010. Energy Efficiency, 9(6), 13511367. https://doi.org/10.1007/s12053-016-9427-x.

ODYSSEE-MURE. (2017). ODYSSEE database. Energy efficiency in Europe. Available online at http://www. indicators.odyssee-mure.eu/ . Accessed 17 Sept 2017.

Pardo Martínez, C. I., \& Silveira, S. (2013). Energy efficiency and $\mathrm{CO} 2$ emissions in Swedish manufacturing industries. Energy Efficiency, 6(1), 117-133. https://doi.org/10.1007/s12053012-9159-5.

Reuter, M., Patel, M. K., \& Eichhammer, W. (2017). Applying expost index decomposition analysis to primary energy consumption for evaluating progress towards European energy efficiency targets. Energy Efficiency, 68(6), 1652. https://doi. org/10.1007/s12053-017-9527-2.

Smit, T. A. B., Hu, J., \& Harmsen, R. (2014). Unravelling projected energy savings in 2020 of EU member states using decomposition analyses. Energy Policy, 74, 271-285. https://doi.org/10.1016/j.enpol.2014.08.030.

Song, Y., \& Zhang, M. (2017). Using a new decoupling indicator (ZM decoupling indicator) to study the relationship between the economic growth and energy consumption in China.
Natural Hazards, 88(2), 1013-1022. https://doi.org/10.1007 /s11069-017-2903-6.

Stenqvist, C. (2015). Trends in energy performance of the Swedish pulp and paper industry. 1984-2011. Energy Efficiency, 8(1), 1-17. https://doi.org/10.1007/s12053-014-9276-4.

Timma, L., \& Blumberga, D. (2014). Index decomposition analysis for energy sectors in Latvia. Energy Procedia, 61, 2180 2183. https://doi.org/10.1016/j.egypro.2014.12.104.

Wachsmuth, J., \& Duscha, V. (2018). Achievability of the Paris targets in the EU- the role of demand-side-driven mitigation in different types of scenarios. Energy Efficiency, 35(3), 238. https://doi.org/10.1007/s12053-018-9670-4.

Wang, W., Liu, X., Zhang, M., \& Song, X. (2014). Using a new generalized LMDI (logarithmic mean Divisia index) method to analyze China's energy consumption. Energy, 67, 617622. https://doi.org/10.1016/j.energy.2013.12.064.

Wang, W., Li, M., \& Zhang, M. (2017). Study on the changes of the decoupling indicator between energy-related $\mathrm{CO} 2$ emission and GDP in China. Energy, 128, 11-18. https://doi. org/10.1016/j.energy.2017.04.004.

Webber, P., Gouldson, A., \& Kerr, N. (2015). The impacts of household retrofit and domestic energy efficiency schemes. A large scale, ex post evaluation. Energy Policy, 84, 35-43. https://doi.org/10.1016/j.enpol.2015.04.020.

Wood, R., \& Lenzen, M. (2006). Zero-value problems of the logarithmic mean Divisia index decomposition method. Energy Policy, 34(12), 1326-1331. https://doi.org/10.1016 j.enpol.2004.11.010.

Xu, X. Y., \& Ang, B. W. (2014). Analysing residential energy consumption using index decomposition analysis. Applied Energy, 113, 342-351. https://doi.org/10.1016/j. apenergy.2013.07.052.

Xu, S.-C., He, Z.-X., \& Long, R.-Y. (2014). Factors that influence carbon emissions due to energy consumption in China. Decomposition analysis using LMDI. Applied Energy, 127, 182-193. https://doi.org/10.1016/j.apenergy.2014.03.093.

Xu, S.-C., He, Z.-X., Long, R.-Y., \& Chen, H. (2016a). Factors that influence carbon emissions due to energy consumption based on different stages and sectors in China. Journal of Cleaner Production, 115, 139-148. https://doi.org/10.1016/j. jclepro.2015.11.050.

Xu, S.-C., He, Z.-X., Long, R.-Y., Chen, H., Han, H.-M., \& Zhang, W.-W. (2016b). Comparative analysis of the regional contributions to carbon emissions in China. Journal of Cleaner Production, 127, 406-417. https://doi.org/10.1016 /j.jclepro.2016.03.149.

Xu, S.-C., Han, H.-M., Zhang, W.-W., Zhang, Q.-Q., Long, R.-Y., Chen, H., \& He, Z.-X. (2017). Analysis of regional contributions to the national carbon intensity in China in different Five-Year Plan periods. Journal of Cleaner Production, 145, 209-220. https://doi.org/10.1016/j.jclepro.2017.01.044.

Xu, S.-C., Gao, C., Miao, Y.-M., Shen, W.-X., Long, R.-Y., Chen, H., Zhao, B., \& Wang, S.-X. (2019). Calculation and decomposition of China's embodied air pollutants in Sino-US trade. Journal of Cleaner Production, 209, 978-994. https://doi. org/10.1016/j.jclepro.2018.10.333.

Yilmaz, M., \& Atak, M. (2010). Decomposition analysis of sectoral energy consumption in Turkey. Energy Sources, Part B: Economics, Planning, and Policy, 5(2), 224-231. https://doi. org/10.1080/15567240802533203. 
Zhang, M., \& Bai, C. (2018). Exploring the influencing factors and decoupling state of residential energy consumption in Shandong. Journal of Cleaner Production, 194, 253-262. https://doi.org/10.1016/j.jclepro.2018.05.122.

Zhang, M., Li, H., Zhou, M., \& Mu, H. (2011). Decomposition analysis of energy consumption in Chinese transportation sector. Applied Energy, 88(6), 2279-2285. https://doi. org/10.1016/j.apenergy.2010.12.077.
Zhang, M., Song, Y., Li, P., \& Li, H. (2016). Study on affecting factors of residential energy consumption in urban and rural Jiangsu. Renewable and Sustainable Energy Reviews, 53, 330-337. https://doi.org/10.1016/j.rser.2015.08.043.

Zhang, M., Bai, C., \& Zhou, M. (2018). Decomposition analysis for assessing the progress in decoupling relationship between coal consumption and economic growth in China. Resources, Conservation and Recycling, 129, 454-462. https://doi. org/10.1016/j.resconrec.2016.06.021. 